\title{
Endothelial cell-targeted pVEGFI65 polyplex plays a pivotal role in inhibiting intimal thickening after vascular injury
}

This article was published in the following Dove Press journal:

International Journal of Nanomedicine

10 September 2015

Number of times this article has been viewed

\author{
Shouqin Tian' \\ Duanwen $\mathrm{CaO}^{2}$ \\ Haijuan Zou' \\ Feng Bai' \\ Zhongjuan Wang' \\ Shirong Pan ${ }^{1,3}$ \\ Min Feng'
}

'School of Pharmaceutical Sciences, Department of Pharmacy, the First Affiliated Hospital, Sun Yatsen University, ${ }^{2}$ Department of Pharmaceutical Sciences, Nanfang Hospital, Southern Medical University, ${ }^{3}$ Key Laboratory on Assisted Circulation, Ministry of Health, Guangzhou, People's Republic of China
Correspondence: Shirong Pan; Min Feng School of Pharmaceutical Sciences, Department of Pharmacy, Sun Yatsen University, Zhongshan II Road 58, Guangzhou, People's Republic of China 510080

Tel +862039943073

Fax +86 2087330396

Email gzpshr@163.com; fengmin@mail. sysu.edu.cn
Abstract: Upregulation of vascular endothelial growth factor (VEGF) expression can inhibit intimal thickening after vascular injury. However, the lack of efficient gene delivery systems leads to insufficient VEGF expression, which prevents its application in gene therapy. In the present study, to improve the delivery of the plasmid vector with the VEGF gene (pVEGF165) to the injured vessel wall, we explored the potentially important difference between endothelial cell-targeted and nontargeted polymeric carriers. The $\alpha_{\mathrm{v}} \beta_{3}$ integrin is overexpressed on activated endothelial cells but not on normal quiescent vessels. In this study, CDG2-cRGD, synthesized by conjugating an $\alpha_{v} \beta_{3}$ integrin-binding cyclic arginylglycylaspartic acid (cRGD) peptide with the Generation 2 polycation polyamidoamine (PAMAMG2)-g-cyclodextrin (termed as CDG2), was developed as a targetable carrier. It was observed that the specific integrin-ligand interactions greatly enhanced cellular internalization of CDG2-cRGD in human umbilical vein endothelial cells (HUVECs), which are notoriously difficult to transfect. Consequently, HUVECs were found to show remarkably high levels of VEGF165 expression induced by the CDG2-cRGD polyplex. Interestingly, VEGF165 overexpression in vivo was more complex than that in vitro, and in vivo assays demonstrated that the stimulus response to balloon injury in arteries could obviously upregulate VEGF165 expression in the saline-treated group, although it was not enough to prevent intimal thickening. In genetransfected groups, intravascular delivery of pVEGF165 with the CDG2-cRGD polyplex into rabbits after vascular injury resulted in a significant inhibition of intimal thickening at 4 weeks, whereas the low therapeutic efficacy in the nontargeted CDG2-treated group was only comparable to that in the saline-treated group. It is becoming clear that the conflicting results of VEGF165 gene therapy in two gene-transfected groups are reflective of the pivotal role of the cRGD-conjugated carriers in achieving the beneficial therapeutic effects of vascular gene therapy.

Keywords: pVEGF165, $\alpha_{v} \beta_{3}$ integrin binding, intimal thickening, vascular gene therapy

\section{Introduction}

Gene therapy holds great promise in treating presently incurable human diseases, such as cancer, ${ }^{1}$ cardiovascular disease, ${ }^{2,3}$ and neurodegenerative disorders. ${ }^{4}$ The number of approved Phase I/II gene therapy clinical trials is steadily increasing, but the lack of safe and efficient gene delivery systems still prevents it from becoming a broadly acceptable therapy. ${ }^{5}$ Polycations comprise a leading class of nonviral gene delivery carriers mostly because of their immense molecular diversity and potential for surface biofunctionalization, ${ }^{6}$ which is able to tune the physicochemical properties to make them suitable for overcoming various delivery barriers such as cellular internalization and endosomal escape. ${ }^{7}$ However, compared with viral carriers, insufficient transfection efficiencies of the polycation gene delivery systems remain their Achilles' heel. ${ }^{8}$ The clinical applicability of polycation-mediated gene delivery is mostly limited by a lack 
of specificity and relatively low transport efficiency across the cellular barriers. ${ }^{9}$ Thus, achieving target-specific and highly efficient in vivo gene delivery is crucial to potently augment clinical effectiveness.

Compared to cell culture application, in vivo polycationmediated gene delivery faces a variety of additional obstacles, such as anatomical size constraints, interactions with biological fluids and extracellular matrix, and binding to a broad variety of nontarget cell types. ${ }^{10}$ Various strategies have been developed to improve the efficiencies of polycation-mediated gene delivery in vivo. To overcome nonspecific binding of the negatively charged endogenous serum proteins and consequently the rapid clearance by the reticuloendothelial system (RES), the antifouling polymer polyethylene glycol (PEG) is widely used for surface modifications. ${ }^{11}$ However, the PEGylation of the polycation results in compromised transfection efficiency, also known as the PEG dilemma. ${ }^{12}$ PEGylated polyplex is associated with lower cellular uptake and dissociates during passage through the liver, which is not desirable for systemic applications. ${ }^{13,14}$ To improve the specificity, ligand conjugation is introduced to provide more accurate delivery of the therapeutic reagents into diseased cells. ${ }^{15}$ However, few ligand-conjugated formulations for systemic administration have reached clinical trials and, to date, none have been clinically approved by the US Food and Drug Administration (FDA). ${ }^{16}$ Bartlett et al ${ }^{17}$ demonstrated that transferrin-targeted small interfering RNA (siRNA) nanoparticles did not increase the biodistribution and tumor localization but enhanced the cellular internalization of the siRNA. Kirpotin et al ${ }^{18}$ also demonstrated that immunoliposomes conjugated to anti-human epidermal growth factor receptor 2 (HER2) monoclonal antibody fragment did not increase the tumor localization in HER2-overexpressing breast cancer xenografts but showed up to sixfold greater intracellular uptake in target cells. These results suggested that existing ligand-conjugated formulations do not seem to exactly surmount extracellular barriers in the human body. ${ }^{19}$ Nevertheless, the ligand-conjugated delivery systems provide benefits in terms of cell internalization on arriving at their target cells. ${ }^{20}$ Because systemic delivery remains one of the biggest challenges in clinical gene therapy, local gene delivery has been an attractive consideration when the target sites are locally confined or readily accessible, such as eyes, lung, and other organs. Local administration can avoid or delay RES uptake, reduce systemic toxicity, provide organ specificity, and help the delivery system reach the target cells. ${ }^{21}$ Recently, local gene delivery systems have yielded promising results, some of which are currently undergoing testing in clinical trials. ${ }^{22}$
Vascular endothelial growth factor (VEGF) is an important angiogenic factor. One of its key functions is stimulating vasculogenesis and angiogenesis. ${ }^{23}$ Therapeutic application of VEGF has been shown to be capable of promoting reendothelialization and inhibiting intimal thickening in in vivo models of vascular injury that resembles balloon angioplastyinduced injury. ${ }^{24}$ Angioplasty is commonly used to open narrowed or blocked blood vessels throughout the body for treating the conditions associated with peripheral artery disease, coronary artery disease, carotid artery stenosis, and renal vascular hypertension. The procedure is performed to open narrowed or blocked arteries by inflating a balloon. ${ }^{25}$ However, the balloon induces acute mechanical arterial injury during expansion and then triggers restenosis. Restenosis is a relatively frequent complication after angioplasty. Upregulation of VEGF expression has great potentials to treat restenosis. The VEGF gene can stimulate endothelial cell proliferation at the site of injury, which protects the vascular wall against excessive proliferation of the vascular smooth muscle cells and consequently inhibits intimal thickening, which is the most important cause of restenosis. ${ }^{26,27}$

The $\alpha_{\mathrm{v}} \beta_{3}$ integrin is one of the key cell surface receptors that are overexpressed on the cell surface of activated endothelial cells but not on normal blood vessels. ${ }^{28}$ Several reports have certified that cyclic arginylglycylaspartic acid peptides (cRGD) have high affinity and selectivity for $\alpha_{v} \beta_{3}$ integrin. ${ }^{29,30}$ Thus, injury-activated endothelial cells can be targeted by the cRGD, which bind to $\alpha_{\mathrm{v}} \beta_{3}$ integrins. In the present study, we developed CDG2-cRGD as targetable delivery carriers by conjugating $\alpha_{\mathrm{v}} \beta_{3}$ integrin-binding cRGD peptides into the nontargeted polycation polyamidoamine (PAMAM) G2-gcyclodextrin (CDG2). Considering the above-mentioned findings, we anticipated that combined application of cRGD conjugation and local delivery would enhance the gene delivery efficiency in vivo. First, the local delivery system provides specificity for the injured vasculature, thereby helping the plasmid vector with the $V E G F$ gene (pVEGF165) reach the vascular endothelial cells. Second, on arriving at the target cells, cRGD conjugation would promote cellular uptake of the pVEGF165 polyplex. To explore the transfer efficiency of the pVEGF165 gene using targeted CDG2-cRGD and nontargeted CDG2 carriers, transfection efficiencies were investigated in different types of cells, including human glioma cells (U87 cells), human umbilical vein endothelial cells (HUVECs), and human embryonic kidney cells (HEK293T cells), with different levels of $\alpha_{v} \beta_{3}$ integrin expression. The $\alpha_{v} \beta_{3}$ integrinbinding specificity of CDG2-cRGD was addressed in HUVECs. Whether delivery of $p V E G F 165$ by CDG2-cRGD could efficiently induce the overexpression of VEGF165 proteins and 
then inhibit intimal thickening were specifically evaluated in a rabbit model of arterial balloon injury.

\section{Materials and methods Materials}

$\alpha$-Cyclodextrin $(\alpha-C D)$ was purchased from Shandong Binzhou Zhiyuan Bio-Technology Co, Ltd (Shandong, People's Republic of China). 1,1'-Carbonyldiimidazole (CDI) and dithiothreitol (DTT) were obtained from SigmaAldrich. $\mathrm{cRGD}$ (molecular weight $=580 \mathrm{Da}$ ) was synthesized by GL Biochem Company (Shanghai, People's Republic of China). 3-(2-Pyridyldithio)propionic acid $N$-hydroxysuccinimide ester (SPDP) was purchased from Thermo Fisher Scientific. PAMAM G2 was synthesized in our laboratory. ${ }^{31}$ Dimethyl sulfoxide (DMSO), methanol, tetrahydrofuran, and diethyl ether were purchased from Guangzhou Reagent Inc (Guangzhou, People's Republic of China). All solvents were distilled to remove any traces of water before use. Dulbecco's Modified Eagle's Medium (DMEM) and penicillin-streptomycin $(10,000 \mathrm{U} / \mathrm{mL})$ were purchased from Hyclone. Fetal bovine serum (FBS), Endothelial Cell Medium, and HUVECs were purchased from ScienCell. U87 cells and HEK293T cells were purchased from the Laboratory Animal Center of Sun Yat-sen University. 3-(4,5-Dimethylthiazol-2-yl)-2,5-diphenyltetrazolium bromide (MTT), Hoechst 33258, and polyethylenimine (PEI) $25 \mathrm{kDa}$ were purchased from Sigma-Aldrich. The plasmids pVEGF165 and pEGFPC1 were constructed previously in our laboratory. Integrin $\alpha_{\mathrm{v}} \beta_{3}$ antibody was purchased from Abcam, USA. Fluorescein isothiocyanate (FITC)-labeled goat polyclonal secondary antibody to mouse immunoglobulinG ( $\mathrm{IgG}$ ) and mouse monoclonal antibody against glyceraldehyde 3-phosphate dehydrogenase (GAPDH) were purchased from Proteintech (Guangzhou, People's Republic of China). Human anti-VEGF165 polyclonal antibody was purchased from Sigma-Aldrich. Polyvinyl difluoride (PVDF) membranes were purchased from Millipore, USA. 2F Fogarty embolectomy catheter was purchased from Edwards Systems Technology, USA. Pentobarbital sodium, penicillin sodium, and heparin were obtained from The First Affiliated Hospital, Sun Yat-sen University (Guangzhou, People's Republic of China).

\section{Synthesis of $c R G D$-conjugated PAMAM CDG2 (CDG2-cRGD)}

PAMAM G2-grafted $\alpha-C D$ (CDG2) as the nontargeted polycation carrier was synthesized according to our previously described method with minor modifications. ${ }^{32}$ CDG2 was prepared by a cross-linking reaction using CDI to couple the primary amines of PAMAM G2 and the hydroxyl groups of $\alpha$-CDs. Briefly, $\alpha$-CD (0.5 g, $0.483 \mathrm{mmol})$ in $25 \mathrm{~mL}$ DMSO was added dropwise to CDI (6.5 g, $0.040 \mathrm{~mol})$ in $25 \mathrm{~mL}$ DMSO under nitrogen. The reaction mixture was stirred at $25^{\circ} \mathrm{C}$ for 24 hours and then poured into tetrahydrofuran/diethyl ether (1:2) mixed solvent to precipitate the product. The resulting solid was dissolved in $25 \mathrm{~mL}$ DMSO and then added dropwise to PAMAM G2 solution ( $38 \mathrm{~g}, 0.012 \mathrm{~mol}$ in $20 \mathrm{~mL}$ DMSO) under nitrogen. The reaction mixture was stirred at $25^{\circ} \mathrm{C}$ for 24 hours and then poured into tetrahydrofuran/diethyl ether (2:1) mixed solvent to precipitate CDG2. The aqueous solution of CDG2 was dialyzed with dialysis tubing (molecular weight cutoff $=7,000 \mathrm{Da}$ ) for 3 days and then freeze-dried to obtain the solid CDG2 product.

The CDG2-cRGD conjugation included two steps (Figure 1A). In the first step, the DMSO solution of bifunctional SPDP (7-28 nmol) was added dropwise into $10 \mathrm{~mL}$ buffer (0.1 M phosphate, $1 \mathrm{mM}$ EDTA, $0.15 \mathrm{M} \mathrm{NaCl}$, pH 7.2) in which CDG2 (80 mg, $4.59 \mathrm{nmol}$ ) was dissolved, with stirring. After the mixture was allowed to react at $25^{\circ} \mathrm{C}$ for 3 hours, the reaction solution was dialyzed for 12 hours against $2 \mathrm{~L}$ of the same buffer. The level of SPDP modification was determined spectrophotometrically at $343 \mathrm{~nm}$ by the release of pyridine-2-thione after reduction of an aliquot with excess of a disulfide-reducing agent, DTT, $0.1 \mathrm{M}$ ) (Thermo Fisher Scientific) according to the manufacturer's protocol. ${ }^{33}$ Then, various amounts of cRGD (7-29 mg) were dissolved in the same buffer and added dropwise to the SPDP-modified CDG2 with continuous stirring under a nitrogen atmosphere. After reacting at $25^{\circ} \mathrm{C}$ for 24 hours, the solution was dialyzed for 72 hours against $2 \mathrm{~L}$ of distilled water. It was then freezedried for 48 hours, and white floccules were obtained. The products obtained were dissolved in deuterium oxide $\left(\mathrm{D}_{2} \mathrm{O}\right)$ and characterized by proton nuclear magnetic resonance ( $\left.{ }^{1} \mathrm{H}-\mathrm{NMR}\right)$ at $400 \mathrm{MHz}$. The CDG2-cRGD products modified with various conjugated numbers of $\mathrm{cRGD}$ were named as CDG2-cRGD-2, CDG2-cRGD-5, and CDG2-cRGD-8, respectively, based on the cRGD couplings. The number of cRGD peptides conjugated to each CDG2 was determined by the above-mentioned analysis of SPDP modification.

\section{Preparation of plasmid DNA/CDG2- cRGD polyplex}

The CDG2-cRGD was self-assembled with pEGFPC1 or pVEGF165 to form plasmid DNA (pDNA)/CDG2-cRGD polyplex (Figure 1B). Briefly, pDNA $(40 \mu \mathrm{g} / \mathrm{mL})$ was mixed with equal volume of CDG2-cRGD in deionized water based on various nitrogen/phosphate $(\mathrm{N} / \mathrm{P})$ ratios of CDG2-cRGD to pDNA ranging from $3: 1$ to $15: 1$. The resulting mixture was 


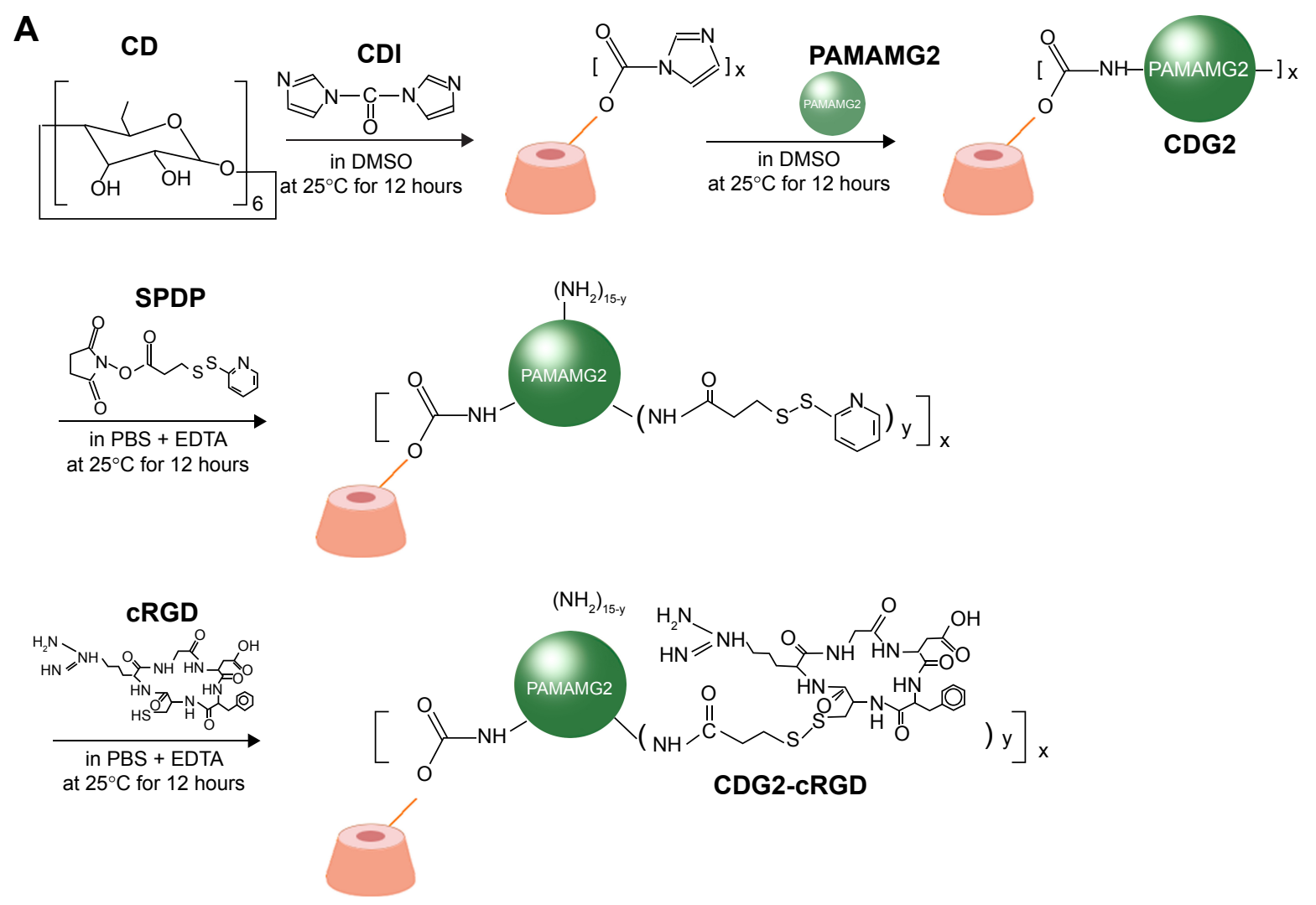

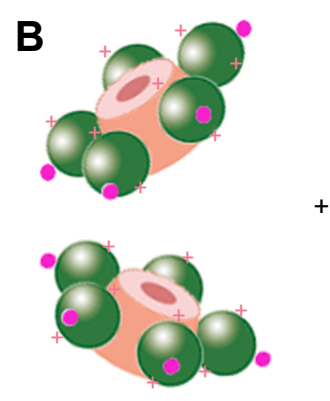

Protonated CDG2-cRGD $: \alpha-C D$

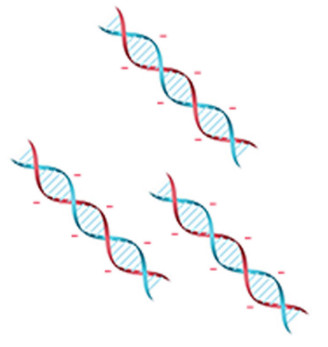

pVEGF165

PAMAMG2

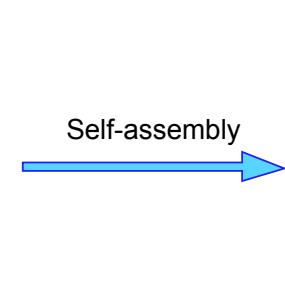

$\bullet$ : cRGD

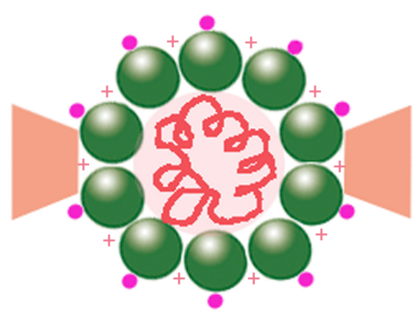

pVEGF165/CDG2-cRGD polyplex

हुํ : Compressed pVEGF165

Figure I Schematic diagram of (A) cRGD-conjugated PAMAMG2-g-cyclodextrin (CDG2-cRGD) and (B) self-assembly of pDNA/CDG2-cRGD polyplex.

Abbreviations: CD, cyclodextrin; CDG2, PAMAMG2-g-cyclodextrin; CDI, I,I'-carbonyldiimidazole; cRGD, cyclic arginylglycylaspartic acid peptide; DMSO, dimethyl sulfoxide; PAMAMG2, Generation 2 polyamidoamine; PBS, phosphate-buffered saline; pDNA, plasmid DNA; pVEGF, plasmid vector with the VEGF gene; SPDP, 3-(2pyridyldithio)propionic acid $\mathrm{N}$-hydroxysuccinimide ester; VEGF, vascular endothelial growth factor.

vortexed for 10 seconds and incubated for 30 minutes at room temperature prior to use. Controls containing pDNA/PEI $25 \mathrm{kDa}$ polyplex at its optimal N/P ratio of 10:1 and pDNA/ CDG2 without cRGD conjugation were also prepared.

\section{Characterization of pDNA/CDG2-cRGD polyplex}

Particle size and $\zeta$-potential measurements

The $\mathrm{pDNA} / \mathrm{CDG} 2-\mathrm{cRGD}$ polyplexes at various N/P ratios were prepared as described in the section "Preparation of plasmid DNA/CDG2-cRGD polyplex". Their particle size and the zeta $(\zeta)$ potential were measured with a Zetasizer Nano Series 90 (Malvern Instruments, Malvern, UK).

\section{Gel retardation assay}

The pDNA/CDG2-cRGD polyplexes containing $0.6 \mu \mathrm{g}$ of pDNA at N/P of $0-1.5$ were freshly prepared. Aliquots $(10 \mu \mathrm{L})$ of polyplex solutions were mixed with gel-loading buffer and electrophoresed on $0.9 \%(\mathrm{w} / \mathrm{v})$ agarose gel containing $0.5 \mathrm{mg} / \mathrm{mL}$ of GoldView dye at $110 \mathrm{~V}$ for 45 minutes. Naked pDNA was used as a control. 


\section{Cell culture}

HEK293T cells and U87 cells were cultured in DMEM and supplemented with $10 \%(\mathrm{v} / \mathrm{v})$ heat-inactivated FBS, 100 units $/ \mathrm{mL}$ penicillin, and $100 \mu \mathrm{g} / \mathrm{mL}$ streptomycin in a $5 \%$ $\mathrm{CO}_{2}$ incubator at $37^{\circ} \mathrm{C}$ under $95 \%$ humidity.

HUVECs (HUVEC-P4 to HUVEC-P7) were grown in Endothelial Cell Medium and supplemented with 5\% heatinactivated FBS (catalog number 0025), 1\% endothelial cell growth supplement (ECGS, catalog number 1052), and 1\% penicillin-streptomycin solution in a $5 \% \mathrm{CO}_{2}$ incubator at $37^{\circ} \mathrm{C}$ under $95 \%$ humidity.

\section{Cytotoxicity of CDG2-cRGD to HUVECs}

Cytotoxicity of CDG2-cRGD toward HUVECs was tested by the MTT assay. The HUVECs were seeded at $2 \times 10^{4}$ cells per well in a 96-well plate with DMEM containing $10 \%$ FBS for 24 hours. The culture media were replaced by fresh medium containing various amounts of polymeric carriers. After 4 hours of incubation, the medium was replaced with complete medium, and cells were incubated for another 48 hours. Then $20 \mu \mathrm{L}$ of MTT solution ( $5 \mathrm{mg} /$ $\mathrm{mL}$ in phosphate-buffered saline (PBS)) was added to each well and incubated for 4 hours. Subsequently, the medium was changed with $200 \mu \mathrm{L}$ of DMSO to dissolve the formazan crystals formed by live cells. Absorbance was measured at $492 \mathrm{~nm}$ using an enzyme-linked immunosorbent assay (ELISA) microplate reader (Bio-Rad). The cell viability was expressed as the percentage of the absorbance of sample to that of the untreated cells.

\section{Quantitation of $\alpha_{v} \beta_{3}$ integrin expression levels on the cell surface}

The HEK293T and U87 cells, as well as HUVECs, were preincubated in DMEM with 10\% FBS for 24 hours. Then, cells were blocked by incubating with 3\% PBS/bovine serum albumin (BSA) solution for 20 minutes, followed by washes with cold PBS three times. Blank cells and secondary antibody cells were incubated with $3 \%$ PBS/BSA solution, while prim + sec cells were treated with integrin $\alpha_{\mathrm{v}} \beta_{3}$ antibody at a concentration of $1 \mu \mathrm{g} / \mathrm{mL}$ in PBS/BSA for 2 hours at $4{ }^{\circ} \mathrm{C}$ in the dark. Then, except for the blank cells, all wells were incubated with FITC-labeled goat polyclonal antibody to mouse IgG at a dilution of 1:100 in PBS/BSA solution for another 1 hour in the dark. Afterward, all cells were detached by the action of $100 \mu \mathrm{L}$ trypsin and resuspended in $300 \mu \mathrm{L}$ PBS. Cell suspensions were analyzed with fluorescence-activated cell sorting (FACS) flow cytometry. Results are expressed as percentage of $\alpha_{v} \beta_{3}$-positive cells.

\section{Evaluation of transfection efficiency}

HEK293T and U87 cells, as well as HUVECs, were seeded into 24-well plates and preincubated for 24 hours. The transfection experiments were conducted at approximately $70 \%$ confluence. Thus, $100 \mu \mathrm{L}$ of pEGFPC 1 polyplex and $0.4 \mathrm{~mL}$ of serum-free medium were added. The final pEGFPC1 concentration was $2.0 \mu \mathrm{g}$ per well. After transfection for 4 hours, the medium was replaced with fresh serum-containing medium, and the cells were incubated for another 48 hours to enable enhanced green fluorescent protein (EGFP) expression. The green fluorescence of transfected cells was observed by fluorescence spectroscopy (Olympus IX71 fluorescence spectroscope). Subsequently, the cells were treated with trypsin/EDTA for 2 minutes, collected by centrifugation, suspended in $0.3 \mathrm{~mL}$ of PBS, and stored on ice until analysis. The percentage of GFP-expressing cells was used to quantify transfection efficiency by flow cytometry using a FACS-Calibur Instrument (Becton-Dickinson) equipped with an argon laser at an excitation wavelength of $488 \mathrm{~nm}$. The filter setting for emission was $530 / 30 \mathrm{~nm}$ bandpass. Data were acquired in the linear mode and visualized, again, in the linear mode.

\section{In vitro targeting studies}

\section{Competitive inhibition assay}

The U87 cells and HUVECs showing high levels of $\alpha_{v} \beta_{3}$ integrin cell surface expression were preincubated for 24 hours. For competitive inhibition experiments, 3-200 $\mu \mathrm{g}$ of free cRGD peptides in PBS was added to the serum-free medium and incubated for 1 hour. The pDNA/CDG2-cRGD-5 polyplexes were then added and incubated for another 4 hours. After incubation, the medium was replaced with complete medium and cells were incubated for another 48 hours. Then, cells were collected by trypsinization and centrifugation. They were analyzed by flow cytometry. CDG2 was used as the control.

\section{Confocal laser scanning microscopy observation}

pDNA was labeled with rhodamine according to the manufacture's protocol (Mirus). The rhodamine-labeled pDNA/ CDG2-cRGD polyplexes at the N/P ratio of 7.5:1 containing $0.5 \mu \mathrm{g}$ of pDNA were freshly prepared before use. HUVECs seeded onto a glass-bottom plate $(\Phi=15 \mathrm{~mm})$ were transfected with various cRGD-conjugated polyplexes in serum-free media for 4 hours. Then, the HUVECs were 
washed with PBS and fixed with 4\% paraformaldehyde for 10 minutes. The nucleus was stained using $10 \mu \mathrm{g} / \mathrm{mL}$ of Hoechst 33258 for 15 minutes. The cellular uptake and intracellular distribution of rhodamine-labeled pDNA polyplexes were observed by confocal laser scanning microscopy (CLSM) and photographed using a Zeiss LSM-710 confocal laser scanning microscope (Carl Zeiss, Germany). Red fluorescence from rhodamine was induced by the $546 \mathrm{~nm}$ excitation and detected at 575-640 nm. Blue fluorescence from Hoechst 33258 was induced by $365 \mathrm{~nm}$ excitation with ultraviolet laser and detected at $430 \mathrm{~nm}$.

\section{ELISA analysis}

Total VEGF protein expression in conditioned medium was determined using the Quantikine Human VEGF Immunoassay ELISA kit (R\&D Systems), according to the manufacturer's protocol. Absorbance readings minus background were converted to pictograms using standard curves from the kit.

\section{Western blotting analysis of VEGFI 65 protein}

At 48 hours posttransfection, HUVECs were lysed in RIPA buffer for 30 minutes at $4^{\circ} \mathrm{C}$ and then centrifuged at $15,000 \times g$ for 12 minutes at $4^{\circ} \mathrm{C}$. The supernatant was transferred, and the total protein of cell extracts was measured using the bicinchoninic acid (BCA) protein assay. All samples (30 $\mu \mathrm{g}$ protein per lane) were separated by $8 \%$ sodium dodecyl sulfate-polyacrylamide gel electrophoresis at $100 \mathrm{~V}$ for 1.5 hours. Subsequently, proteins were transferred electrophoretically onto a PVDF membrane for 2 hours at $250 \mathrm{~mA}$ with a Bio-Rad blotter. To minimize nonspecific binding, the membrane was blocked using 5\% nonfat milk powder in PBS buffer containing 1\% Tween 20 for 1 hour at room temperature. The particular antibody and protein combination was initiated incubation of proteins with primary antibodies (human anti-VEGF165 polyclonal antibody and rabbit anti-GAPDH monoclonal antibody) at $4{ }^{\circ} \mathrm{C}$ overnight, followed by incubation with horseradish peroxidase-conjugated goat anti-mouse IgG as secondary antibodies. Protein bands were ultimately detected by the enhanced chemiluminescence method.

\section{In vivo inhibition of intimal thickening after vascular injury}

A rabbit model of arterial balloon injury

New Zealand White rabbits ( $n=6$ in each group), weighing $1.5-2.0 \mathrm{~kg}$, were anesthetized with $3 \%$ pentobarbital sodium ( $1 \mathrm{~mL} / \mathrm{kg}$ body weight). After exposure of the left common carotid artery, a 2F Fogarty balloon catheter (Edwards Systems Technology, USA) was introduced into the carotid artery to develop the animal model of balloon-induced vascular injury. The balloon was inflated until contact was made with the vascular endothelium. The arteries were denuded by gentle advancement and withdrawal of the catheter three times. ${ }^{34}$ Upon removal of the balloon catheter, a PE-10 catheter (Boston Scientific, USA) was inserted into the denuded rabbit arteries for local gene administration. Polyplex-mediated gene transfer was performed at 6 ATM for 30 minutes. CDG2-cRGD polyplex and CDG2 polyplex containing 20 $\mu \mathrm{g}$ pVEGF1 65 at the N/P $=7.5$ were used in a total volume of $200 \mu \mathrm{L}$ of $0.9 \% \mathrm{NaCl}$. Animals were killed and samples were collected at 28 days after the gene transfer. This study was performed in strict accordance with the recommendations in the Guide for the Care and Use of Laboratory Animals of the National Institutes of Health (http://grants.nih.gov/grants/ olaw/guide-for-the-care-and-use-of-laboratory-animals.pdf). The protocol was approved by the Committee on the Ethics of Animal Experiments of Sun Yat-sen University (permit number: 20090305001).

\section{Histology and morphometry}

Representative sections of the carotid artery were fixed in $4 \%$ paraformalin and embedded in paraffin. Next, $5-\mu$ m-thick cross sections were cut, routinely stained with hematoxylin and eosin, and then were photographed (Olympus BX51, Japan). The cross-sectional areas of the intimal and medial regions of the sections were measured with an imageanalyzing software package (Image-Pro PLUS). The intimal and medial cross-sectional areas and intimal-to-medial (I/M) area ratio of each artery were determined. ${ }^{35}$

\section{Determination of VEGFI 65 protein expressed in vascular tissue}

Two days after balloon-induced vascular injury, the left common carotid artery was obtained from the animals carefully, followed by washing with cold $0.9 \% \mathrm{NaCl}$. The vascular fragments were opened longitudinally and homogenized using a homogenizer containing $500 \mu \mathrm{L}$ RIPA and $1 \%$ phenylmethanesulfonyl fluoride (PMSF) in an ice bath. The vascular tissue homogenates were then centrifuged at $15,000 \times g$ for 30 minutes at $4^{\circ} \mathrm{C}$. Total protein concentration in tissue homogenates was assessed with the BCA protein assay kit. VEGF165 protein expressed in vascular tissue was detected by Western blot analysis as described herein.

\section{Statistical analysis}

Data were expressed as the mean \pm the standard error of the mean. Statistical comparisons were performed using one-way 
analysis of variance. $P$-values $<0.05$ were considered statistically significant, and those $<0.01$ or $<0.001$ were considered highly statistically significant.

\section{Results}

\section{Synthesis and characterization of CDG2- cRGD}

The $\alpha_{v} \beta_{3}$ integrin is a cell surface receptor that shows highlevel expression in activated endothelial cells following vascular injury. Therefore, one of the most active and selective targeting ligands for the $\alpha_{\mathrm{v}} \beta_{3}$ integrin, cRGD, was used in this study. We designed CDG2-cRGD as gene carriers for pVEGF165 delivery for inhibiting intimal thickening after vascular injury. As described in the "Introduction" section, cRGD conjugation was expected to promote cellular uptake of the pVEGF165 polyplex. Here, CDG2-cRGD with various numbers of conjugated cRGD was synthesized by a two-step cross-linking procedure, as shown in Figure 1A: 1) $\alpha$-CD was grafted onto PAMAM G2 through a CDI-mediated reaction. CDI activated the hydroxyl groups of $\alpha-C D$ to form active imidazolyl carbamate intermediates and subsequently attacked the primary amine groups of PAMAM G2 to generate CDG2 . 2) cRGD peptides were conjugated to CDG2 molecules by SPDP coupling. Bifunctional SPDP was reacted separately with the amine groups of CDG2 to form amide bonds via the $N$-hydroxysuccinimide ester group. The other end of the functional pyridyl disulfide group reacted with the sulfhydryl residue of cRGD to create a disulfide bond. The CDG2 conjugates were confirmed by ${ }^{1} \mathrm{H}-\mathrm{NMR}$ analysis (Figure $\mathrm{S} 1$ ). The average number of cRGD couplings in one CDG2-cRGD molecule was 1.9, 5.4, and 7.2, determined by the pyridine-2-thione release assay as shown in Table 1.

Primary endothelial cells, such as HUVECs, are notoriously susceptible to the toxic effects of transfection reagents. ${ }^{36}$ The cytotoxicity of various gene carriers toward HUVECs was evaluated by the MTT assay (Figure 2A). The half-maximal inhibitory concentration $\left(\mathrm{IC}_{50}\right)$ of PEI $25 \mathrm{kDa}$ was $36.3 \mu \mathrm{g} / \mathrm{mL}$, while the cell viability of CDG2-cRGD and CDG2 was $>80 \%$ at the same concentration and maintained at $>50 \%$ at the high concentration of $400 \mu \mathrm{g} / \mathrm{mL}$. It was suggested that both CDG2-cRGD and CDG2 induced much less cytotoxicity than PEI $25 \mathrm{kDa}$ to HUVECs. Low toxicity of polycationic gene carriers is one critical prerequisite for in vivo applications of vascular gene transfer.

\section{Characterization of pDNA/CDG2-cRGD polyplex}

The pDNA/CDG2 polyplex without cRGD modification at the N/P ratio of 7.5 was about $151.4 \mathrm{~nm}$, according to the dynamic light scattering measurement, and its $\zeta$-potential was $17.73 \mathrm{mV}$ (Figure 2B). Upon cRGD modification of $\mathrm{CDG} 2$, the $\zeta$ potential of pDNA/CDG2-cRGD polyplex slightly increased from $17.73 \mathrm{mV}$ to $20.05 \mathrm{mV}$ with the increase of cRGD-coupling number. CDG2-cRGD polyplex with coupling numbers of cRGD of 1.9 and 5.4 did not show any statistically significant changes in the particle size compared with the CDG2 polyplex, while the CDG2-cRGD-8 polyplex with coupling number of cRGD of 7.2 obviously showed increased particle size. The binding and compaction of pDNA by CDG2-cRGD were assessed by gel retardation assay. As presented in Figure $2 \mathrm{C}$, there was the trend that the N/P ratios for achieving complete pDNA compaction decreased with increasing cRGD-coupling number. These results suggested that cRGD conjugation could assist CDG2 to condense pDNA, most probably because cRGD contained amine groups involved in electrostatic interactions with negatively charged pDNA. Particle size and $\zeta$ potential of the pDNA/CDG2-cRGD-5 polyplex at the N/P ratio of 7.5/1 with average number of cRGD of 5.4, which was used in pVEGF165 delivery studies both in vitro and in vivo, were $167 \mathrm{~nm}$ and $18.8 \mathrm{mV}$, respectively.

\section{In vitro gene transfer with CDG2-cRGD} Quantitation of $\alpha_{v} \beta_{3}$ integrin surface expression Three cell lines, HEK293T, U87, and HUVECs, with different levels of $\alpha_{v} \beta_{3}$ integrin expression, were selected to investigate $\alpha_{v} \beta_{3}$-mediated gene transfer of cRGD-modified carriers. Before transfection experiments, the levels of $\alpha_{v} \beta_{3}$ integrin expression on the cell surface were analyzed by FACS flow cytometry, as shown in Figure 3. The HUVECs

Table I Experimentally determined extents of cRGD conjugation

\begin{tabular}{llll}
\hline Samples & Average number of SPDP per CDG2 $^{\mathbf{a}}$ & Average number of cRGD per CDG2 $^{\mathbf{a}}$ & Molecular weight (Da) $^{\mathbf{b}}$ \\
\hline CDG2-cRGD-2 & 2.8 & 1.9 & 19,077 \\
CDG2-cRGD-5 & 4.6 & 5.4 & 22,157 \\
CDG2-cRGD-8 & 9.5 & 7.2 & 23,74 ।
\end{tabular}

Notes: aMeasured by ultraviolet spectrophotometer at $343 \mathrm{~nm}$; ${ }^{b}$ calculated based on the molecular weight of CDG2, SPDP, and cRGD.

Abbreviations: CD, cyclodextrin; CDG2, PAMAMG2-g-cyclodextrin; cRGD, cyclic arginylglycylaspartic acid peptide; PAMAMG2, Generation 2 polyamidoamine; SPDP, 3-(2-Pyridyldithio)propionic acid $\mathrm{N}$-hydroxysuccinimide ester. 

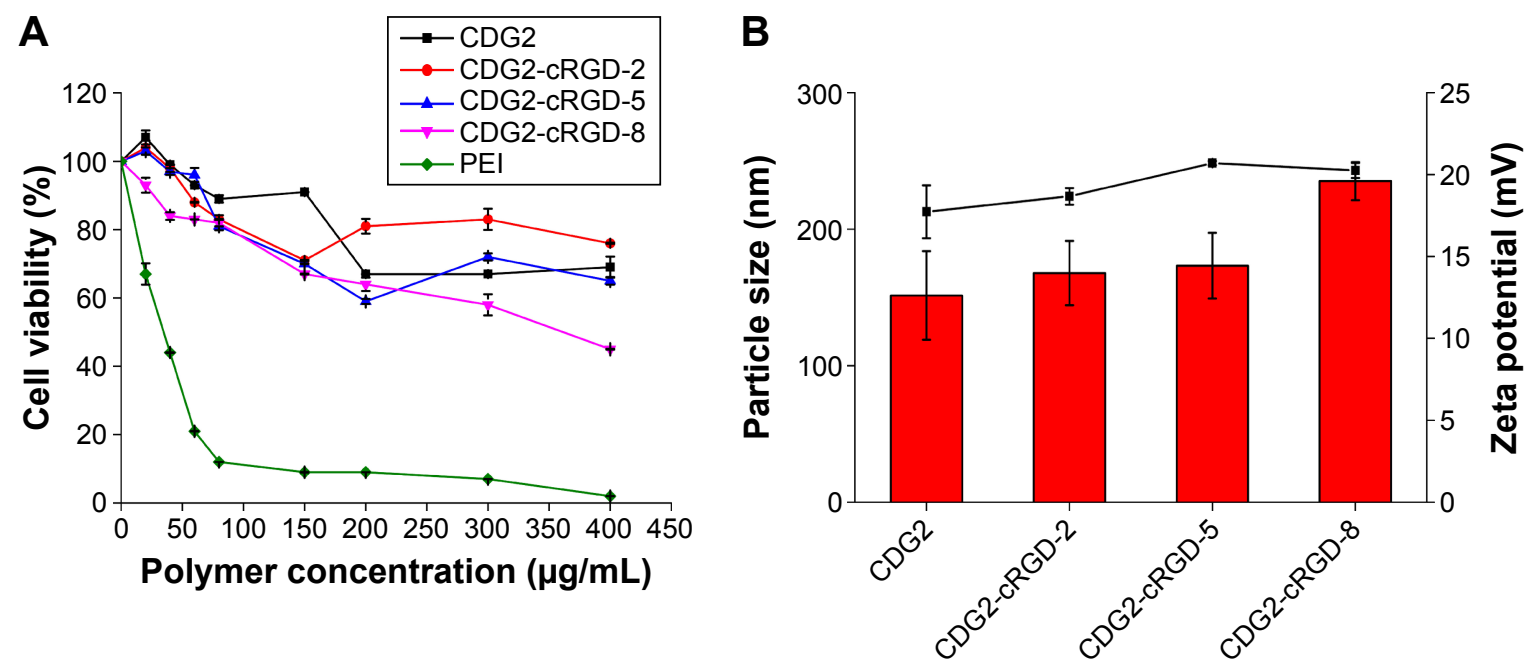

\section{C}
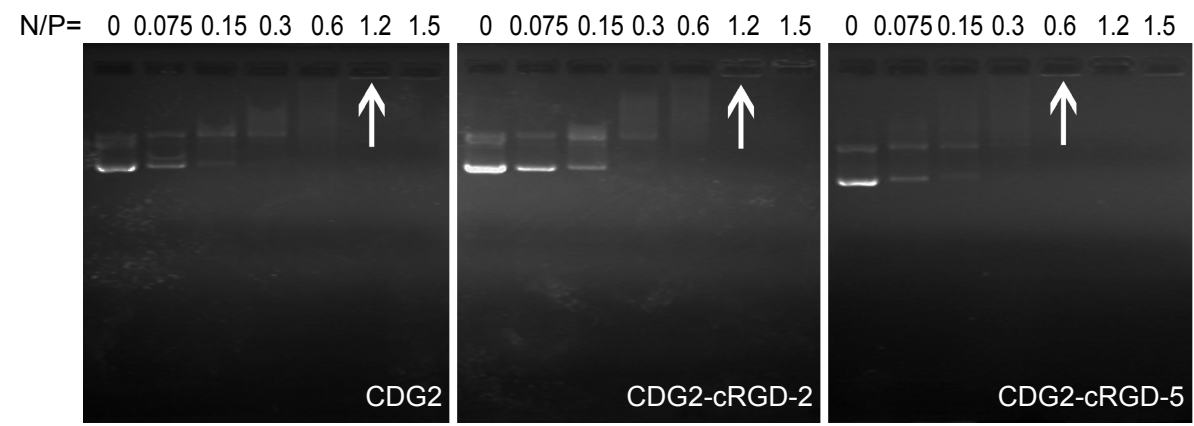

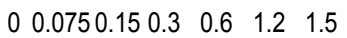

Figure 2 Characterization of DNA/CDG2-cRGD polyplex.

Notes: (A) Viabilities of cells at various concentrations of CDG2 and cRGD in HUVECs. (B) Size and zeta ( $\zeta$ ) potential of the pDNA/CDG2-cRGD polyplex at the N/P ratio of 7.5:I. The concentrations of both CDG2-cRGD and CDG2 were $100 \mu \mathrm{g} / \mathrm{mL}$. (C) The binding and compaction of pDNA by CDG2-cRGD-conjugated with various amounts of CRGD. The arrows indicate the N/P ratios for achieving complete pDNA compaction.

Abbreviations: CD, cyclodextrin; CDG2, Generation 2 polyamidoamine-g-cyclodextrin; cRGD, cyclic arginylglycylaspartic acid peptide; HUVECs, human umbilical vein endothelial cells; N/P, nitrogen-to-phosphate ratio; pDNA, plasmid DNA; PEI, polyethylenimine.

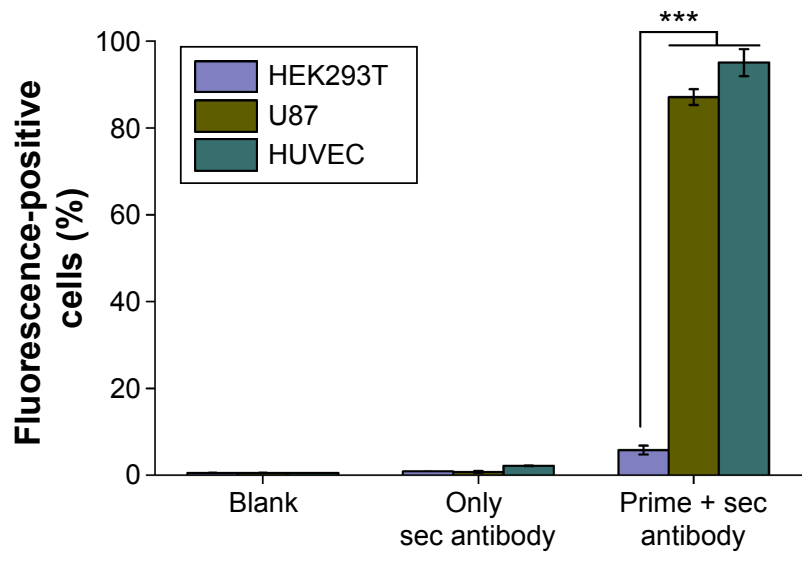

Figure 3 The expression level of $\alpha_{v} \beta_{3}$ integrin on cell surface was analyzed by flow cytometry.

Notes: Three cell lines expressing $\alpha_{4} \beta_{3}$ integrin were stained with $\alpha_{4} \beta_{3}$ antibody. Staining was visualized using an FITC-labeled goat polyclonal secondary antibody to mouse IgG monoclonal antibody. Results are expressed as percentage of $\alpha_{v} \beta_{3}$ positive cells $(* * * P<0.001)$.

Abbreviations: FITC, fluorescein isothiocyanate; HEK293T, human embryonic kidney cells; HUVECs, human umbilical vein endothelial cells; IgG, immunoglobulinG; Sec, secondary; U87, human glioma cells. and U87 cells expressed high levels of $\alpha_{v} \beta_{3}$ integrin, while the HEK293T cells exhibited very low surface expression levels of $\alpha_{v} \beta_{3}$ integrin. HUVECs expressed 16-fold more $\alpha_{v} \beta_{3}$ integrin on their surface (95.01\%) compared to HEK293T cells $(5.78 \%)$.

\section{Transfection efficiency of CDG2-cRGD}

The relative transfection efficiencies of CDG2-cRGD conjugates for EGFP expression were evaluated using FACS analysis in several different cell lines with varying levels of $\alpha_{v} \beta_{3}$ integrin receptor expression (Figure 4 and Figure S2). As presented in Figure 4A, in HEK293T cells, with very low levels of $\alpha_{\mathrm{v}} \beta_{3}$ integrin expression - confirmed by our experiments, CDG2-cRGD conjugates showed reduced transfection efficiency, especially at high coupling ratios of cRGD, as compared to CDG2 without cRGD conjugation at the same N/P ratios $(P<0.01)$. However, it was clear that after conjugation of cRGD onto CDG2, transfection efficiency 

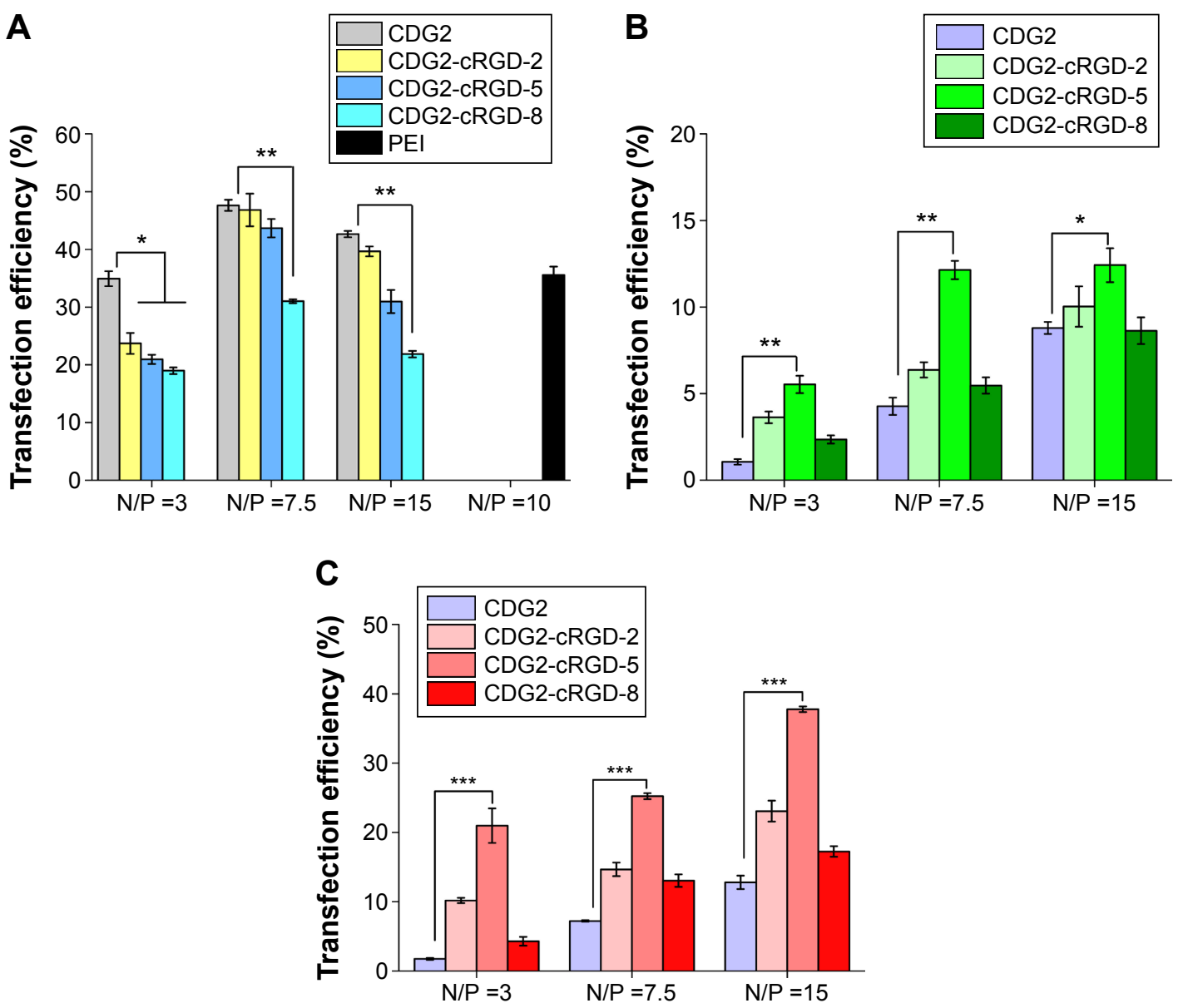

Figure 4 Fraction of EGFP-positive cells after transfection.

Notes: (A) HEK293T cells with a low level of $\alpha_{v} \beta_{3}$ integrin expression. (B) HUVECs and (C) U87 cells with high levels of $\alpha_{v} \beta_{3}$ integrin expression on the cell surface $(* P<0.05 ; * * P<0.01 ; * * * P<0.00 I)$. The concentration of polymer was $3.33 \mu \mathrm{g} / \mathrm{mL}, 8.33 \mu \mathrm{g} / \mathrm{mL}$, and I6.67 $\mu \mathrm{g} / \mathrm{mL}$, corresponding to the $\mathrm{N} / \mathrm{P}$ ratios of $3 / \mathrm{I}, 7.5 / \mathrm{I}$, and I5/I, respectively.

Abbreviations: CD, cyclodextrin; CDG2, PAMAMG2-g-cyclodextrin; cRGD, cyclic arginylglycylaspartic acid peptide; PAMAMG2, Generation 2 polyamidoamine; EGFP, enhanced green fluorescent protein; HEK293T, human embryonic kidney cells; HUVECs, human umbilical vein endothelial cells; N/P, nitrogen-to-phospahate ratio; PEI, polyethylenimine; $\mathrm{U} 87$, human glioma cells.

was significantly promoted in both HUVECs and U87 cells showing high levels of $\alpha_{\mathrm{v}} \beta_{3}$ integrin expression on the cell surface (Figure 4B and C). CDG2-cRGD-5, with average number of cRGD of 5.4, offered the most obvious benefit in terms of transfection efficiency $(P<0.01)$. The transfection efficiency of CDG2-cRGD-5 at the N/P ratio of 7.5 was 2.2fold higher than that of CDG2 in HUVECs.

\section{In vitro $\alpha_{\mathrm{v}} \beta_{3}$ targeting of CDG2-cRGD Competitive binding assay}

To address the specificity of the CDG2-cRGD for $\alpha_{v} \beta_{3}$ integrin, we performed competition studies on HUVECs and U87 cells that express high levels of this integrin (Figure 5). HUVECs and U87 cells were pretreated with an excess of free cRGD and, subsequently, were transfected by CDG2cRGD-5 and CDG2 polyplexes. The performance of CDG2 was not affected by the presence of free cRGD as expected, whereas free cRGD significantly reduced the transfection efficiencies of CDG2-cRGD-5, whether in HUVECs or in U87 cells (Figure 5A and B). It was found that free inhibition of the binding of the carriers by cRGD resulted in 3.2-fold (100 $\mu \mathrm{g}$ of free cRGD) and 2.0-fold ( $24 \mu \mathrm{g}$ of free cRGD) lower transfection efficiencies for CDG2-cRGD-5 in HUVECs $(P<0.01)$ and U87 cells $(P<0.001)$, respectively, than those in the absence of competitive cRGD, as shown in Figure $5 \mathrm{C}$ and $\mathrm{D}$. These results suggested that the binding specificity of cRGD to $\alpha_{v} \beta_{3}$ integrin contributed to the high transfection efficiencies of CDG2-cRGD, compared with those of CDG2 without cRGD conjugations, in $\alpha_{v} \beta_{3}$ positive cells.

\section{Observations of cellular uptake in HUVECs}

To observe $\alpha_{\mathrm{v}} \beta_{3}$ targeting of CDG2-cRGD in HUVECs, the rhodamine-labeled pDNA polyplex (in red) at the $\mathrm{N} / \mathrm{P}$ ratio 
A

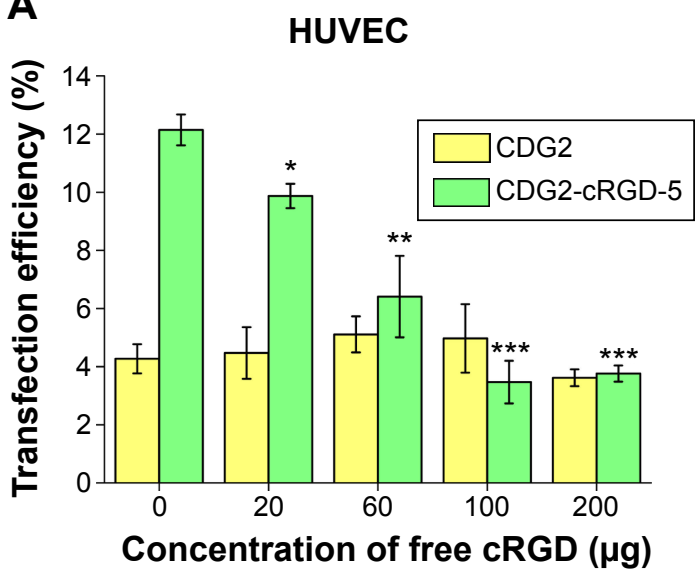

C

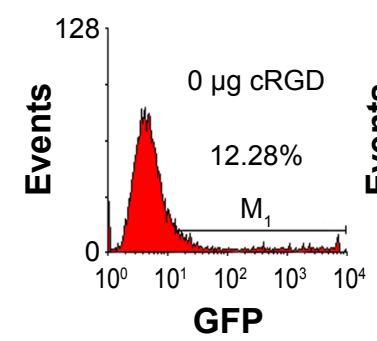

HUVEC

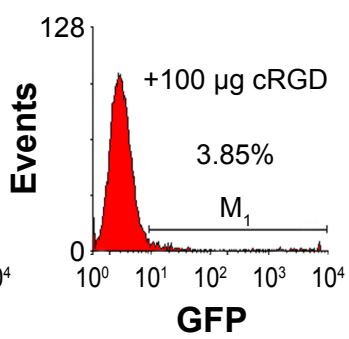

B

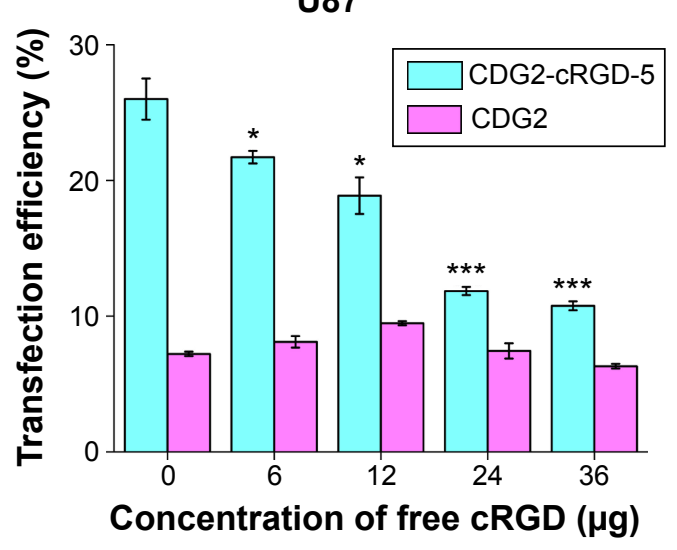

D

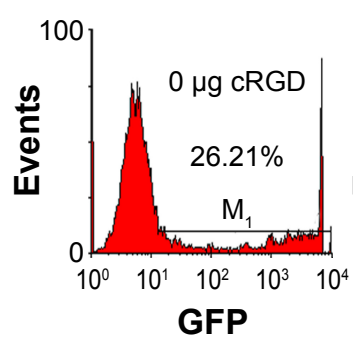

U87

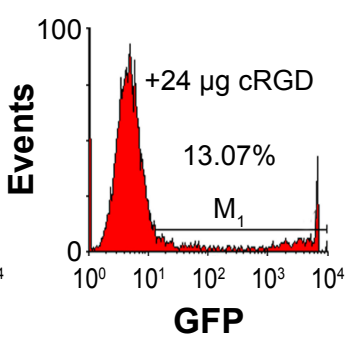

Figure 5 Competitive inhibition assay.

Notes: Transfection efficiencies of CDG2-cRGD-mediated gene delivery were inhibited in the presence of competitive free cRGD both in (A) HUVECs and (B) U87 cells possessing high levels of $\alpha_{v} \beta_{3}$ integrin expression on the cell surface. Representative flow cytometric histograms indicated these inhibition effects of free cRGD at concentrations of (C) $100 \mu \mathrm{g} / \mathrm{mL}$ for HUVECs and (D) $24 \mu \mathrm{g} / \mathrm{mL}$ for U87 cells ( $* P<0.05$; $* * P<0.01$; $* * * P<0.001)$. The transfection concentrations of both CDG2 and CDG2cRGD were $8.33 \mu \mathrm{g} / \mathrm{mL}$.

Abbreviations: CD, cyclodextrin; CDG2, PAMAMG2-g-cyclodextrin; cRGD, cyclic arginylglycylaspartic acid peptide; PAMAMG2, Generation 2 polyamidoamine; GFP, green fluorescent protein; HUVECs, human umbilical vein endothelial cells; U87, human glioma cells.

of 7.5/1 was incubated with HUVECs, and these cells (nuclei depicted in blue) and pDNA polyplexes (in red) were imaged by CLSM, as shown in Figure 6. CLSM demonstrated that, in contrast to the low uptake of pDNA/CDG2 polyplex by HUVECs, the cellular uptake of pDNA/CDG2-cRGD polyplex was remarkably high for the same incubation times. Furthermore, among the cRGD conjugates with various coupling ratios, CDG2-cRGD-5 was the most efficient carrier for delivering pDNA into the HUVECs and preferentially accumulated in the cytoplasm around the nucleus, confirming the transfection results.

\section{Overexpression of VEGFI65 protein in HUVECs transfected with CDG2-cRGD ELISA forVEGFI65 expression}

Our results indicated that the most significant enhancement of transfection efficiency in HUVECs was obtained with the formula containing pDNA/CDG2-cRGD-5 polyplex at the N/P ratio of 7.5/1. We next used this formula for pVEGF165 gene delivery. To test whether the pVEGF165/CDG2-cRGD-5 polyplex could induce VEGF165 protein synthesis, we determined the levels of VEGF165 protein in the media of HUVECs. After transfection with pVEGF165/CDG2cRGD-5 polyplex, the supernatant of the medium with HUVECs showed 11.0-fold and 15.9-fold increased VEGF165 levels, in comparison with HUVECs transfected with CDG2 $(P<0.001)$ and untreated HUVECs $(P<0.001)$, respectively, as shown in Figure 7A.

\section{Western blot analysis for VEGFI 65 expression}

Western blot analysis was performed to further check whether CDG2-cRGD-5 could efficiently deliver pVEGF165 and induce pVEGF165 protein expression in HUVECs. By using a human anti-VEGF polyclonal antibody against VEGF, three bands were detected at $40 \mathrm{kDa}, 43 \mathrm{kDa}$, and $75 \mathrm{kDa}$. The predominant band was at $43 \mathrm{kDa}$. The intensity of the band in HUVECs transfected with CDG2-cRGD-5 was obviously increased compared with the same in CDG2-treated and untreated cells (Figure 7B). GAPDH (37 kDa) was also examined to verify equal protein loading in each lane. 


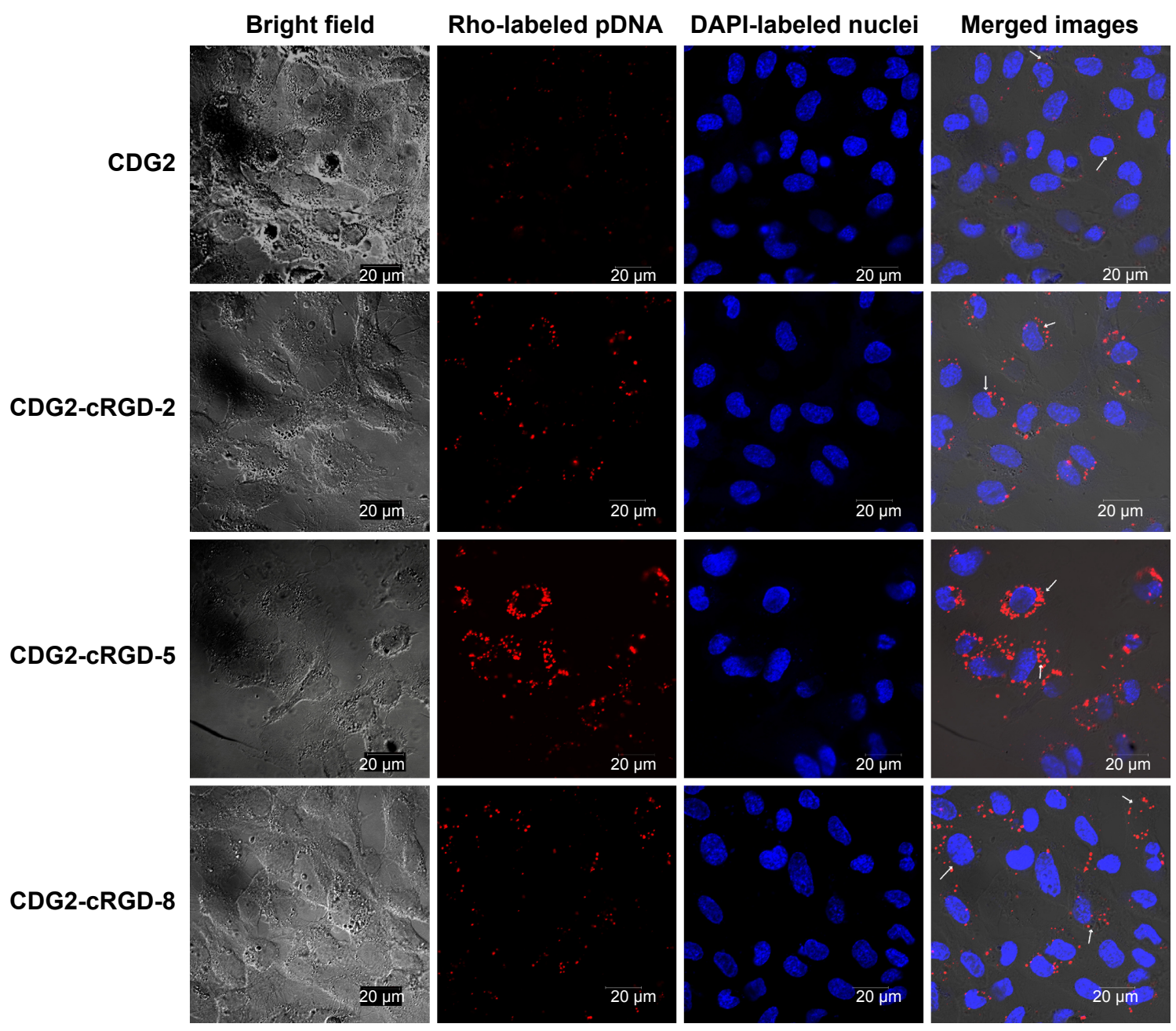

Figure 6 Confocal microscope images of cellular uptake and accumulations of pDNA/CDG2-cRGD polyplexes at various cRGD contents in HUVECs.

Notes: Arrows indicate the red rhodamine-labeled pDNA and blue Hoechst 33258-stained nuclei. The concentrations of both CDG2 and CDG2-cRGD were $8.33 \mu \mathrm{g} / \mathrm{mL}$. Abbreviations: CD, cyclodextrin; CDG2, PAMAMG2-g-cyclodextrin; CRGD, cyclic arginylglycylaspartic acid peptide; DAPI, 4',6-diamidino-2-phenylindole; HUVECs, human umbilical vein endothelial cells; PAMAMG2, Generation 2 polyamidoamine; pDNA, plasmid DNA.

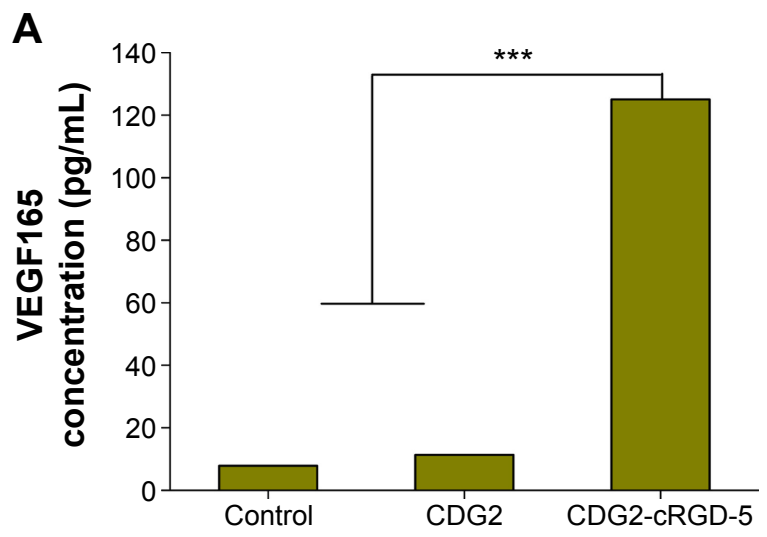

B

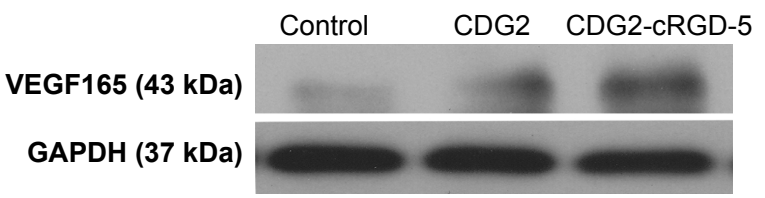

Figure 7 VEGFI65 protein overexpression in HUVECs.

Notes: (A) Quantification of VEGFI65 protein expression in HUVEC culture media by ELISA analysis (***P<0.00I). The concentrations of CDG2 and CDG2-cRGD were $8.33 \mu \mathrm{g} / \mathrm{mL}$. (B) Western blot analysis of VEGFI65 expression in HUVECs. GAPDH (37 kDa) was used as an internal control.

Abbreviations: CD, cyclodextrin; CDG2, PAMAMG2-g-cyclodextrin; cRGD, cyclic arginylglycylaspartic acid peptide; ELISA, enzyme-linked immunosorbent assay; GAPDH, glyceraldehyde 3-phosphate dehydrogenase; HUVECs, human umbilical vein endothelial cells; PAMAMG2, Generation 2 polyamidoamine; VEGF, vascular endothelial growth factor. 


\section{In vivo inhibition of intimal thickening after vascular injury} CDG2-cRGD-mediated transgene expression in vivo Having established that pVEGF165/CDG2-cRGD-5 polyplex could efficiently induce pVEGF165 protein overexpression in HUVECs, the optimized formula was used to transfect the injured common carotid artery undergoing balloon angioplasty in a rabbit model. The levels of VEGF165 protein expression in the injured arteries were evaluated using Western blot analysis. Administration of pVEGF165/ CDG2-cRGD-5 polyplex $(200 \mu \mathrm{L}, 0.1 \mathrm{mg} / \mathrm{mL}$, and N/P =7.5) resulted in a significant increase in VEGF165 protein expression at the selected time point of 2 days after balloon angioplasty, as shown in Figure 8A. This time point was selected on the basis of previously reported data ${ }^{37}$ in different animal models suggesting that VEGF expression reached a maximal level within the first 3 days after administration of therapeutic reagents. The relative VEGF165 protein level in the CDG2-cRGD-5 group was markedly higher than that in the saline-treated group $(P<0.01)$ and the control group $(P<0.001)$ (Figure 8B).

On assessing the specific targeting of vascular endothelial cells by cRGD conjugation, the injured arteries in the CDG2cRGD-5 group exhibited significantly increased VEGF165 expression $(P<0.01)$, compared with the injured arteries of CDG2-treated animals. It was noted that the saline-treated group also showed relatively high VEGF165 protein expression in comparison with that of the control group without balloon angioplasty $(P<0.001)$, mostly due to the stimulus response consequent to balloon injury to arteries, which could cause upregulation of VEGF expression in vivo. ${ }^{38}$ However, the relative VEGF165 protein level in the CDG2-treated group was not significantly different from that in the salinetreated group.

\section{Histomorphometry}

To assess the effect of CDG2-cRGD-mediated delivery of the $p V E G F 165$ gene on inhibition of intimal thickening after vascular injury, the arteries were harvested at 4 weeks after balloon-induced arterial injury and transfection. Hematoxylineosin staining and subsequent morphometric analysis of all the treatment groups showed neointima formation in contrast to the noninjured control group (Figure 9A). Animals treated with the pVEGF165/CDG2 polyplex exhibited obvious intimal thickening that was not significantly different compared with the saline-treated group, whereas treatment with pVEGF165/CDG2-cRGD-5 polyplex resulted in significantly less intimal thickening in comparison with the saline-treated group. Furthermore, to determine the extent of neointima formation, the intima-to-media (I/M) ratios were calculated (Figure 9B). The I/M ratio of the CDG2-cRGD-5-treated group was $0.39 \pm 0.13$. In contrast, the $\mathrm{I} / \mathrm{M}$ ratio of the $\mathrm{CDG} 2$ group was $0.97 \pm 0.22$, comparable to that of the saline-treated group. These results suggested that CDG2-cRGD-5-mediated delivery of the $p V E G F 165$ gene could efficiently inhibit intimal thickening, compared with the CDG2- and saline-treated groups. Moreover, the average intimal areas in the CDG2cRGD-5, CDG2, and $0.9 \% \mathrm{NaCl}$ groups were $64,243 \mu^{2}$, $169,728 \mu \mathrm{m}^{2}$, and $190,436 \mu \mathrm{m}^{2}$, respectively, calculated using Image Pro Plus 6.0 software, as shown in Table 2.

\section{Discussion}

Restenosis has remained a major clinical problem after coronary and peripheral artery angioplasty. Upregulation of
A

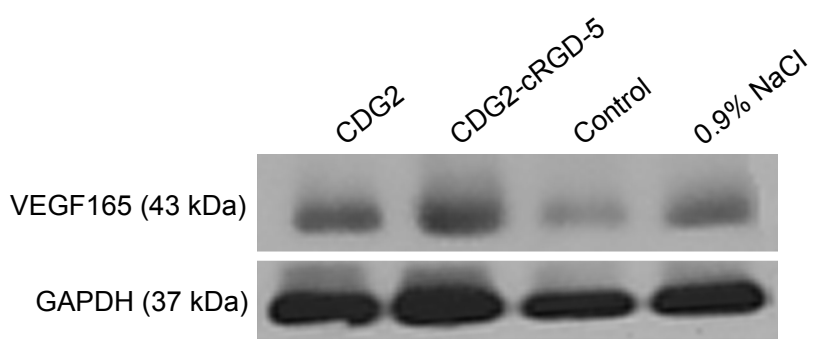

B

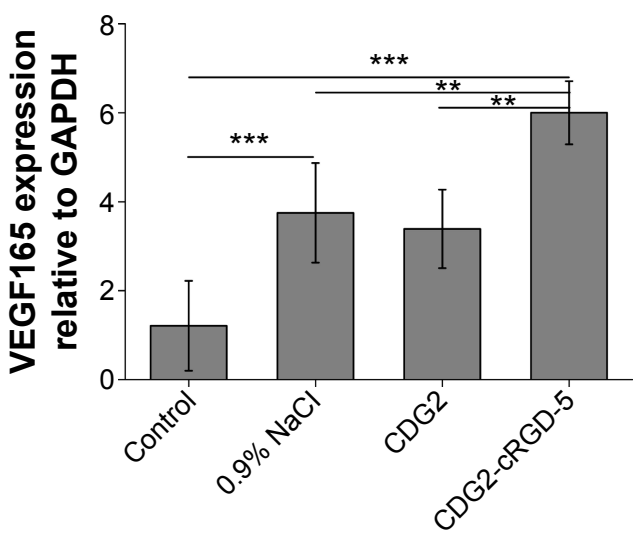

Figure 8 VEGFI65 protein expressions in injured arteries at the selected time point of 2 days after balloon angioplasty.

Notes: (A) Western blot analysis of VEGFI65 protein ( $43 \mathrm{kDa})$ levels. GAPDH (37 kDa) was used as an internal control. (B) Semiquantitative densitometric analysis of relative VEGFI65 protein level (**P<0.0I; ***P<0.00I). The concentrations of both CDG2 and CDG2-cRGD were $500 \mu g / \mathrm{mL}$.

Abbreviations: CD, cyclodextrin; CDG2, PAMAMG2-g-cyclodextrin; cRGD, cyclic arginylglycylaspartic acid peptide; GAPDH, glyceraldehyde 3-phosphate dehydrogenase; PAMAMG2, Generation 2 polyamidoamine; VEGF, vascular endothelial growth factor. 
A

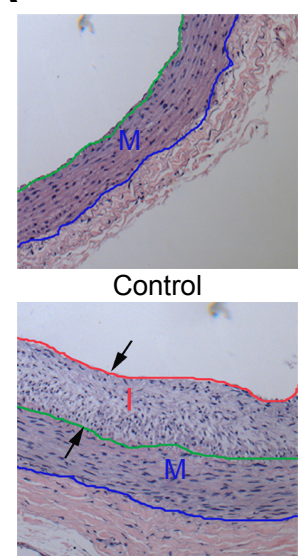

CDG2

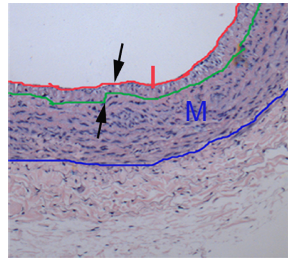

CDG2-cRGD-5

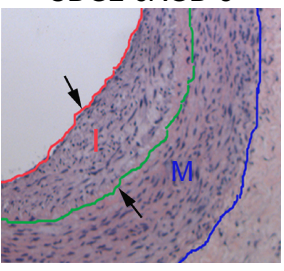

$0.9 \% \mathrm{NaCl}$
B

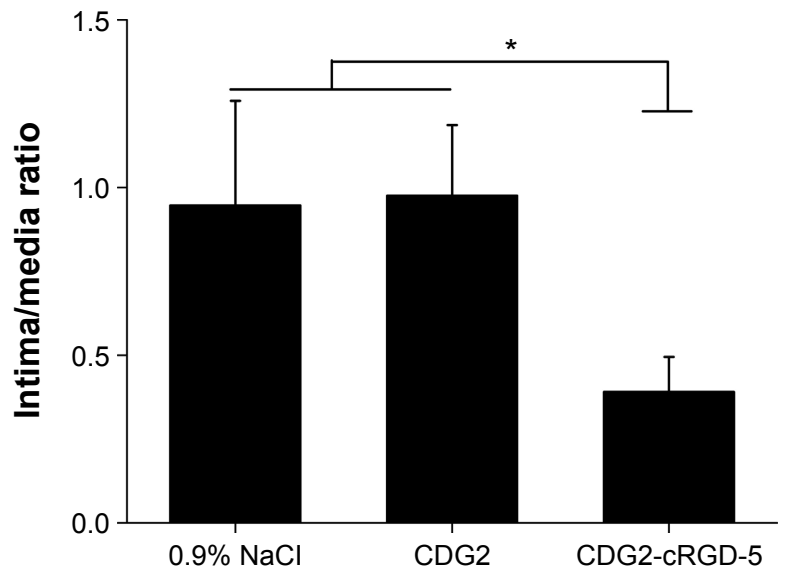

Figure 9 Effects of pVEGFI65 gene delivery on inhibition of intimal thickening after vascular injury.

Notes: (A) Representative hematoxylin-eosin sections of noninjured and injured carotid arteries at 4 weeks after surgery and treatment with pVEGFI65/CDG2-cRGD-5 polyplex, pVEGF165/CDG2 polyplex, or saline ( $n=6$ in each group). The arrows indicate the neointima formation. The distance between arrows represents the neointimal thickness. Original magnifications: $\times 200$. (B) Average intima/media $(\mathrm{I} / \mathrm{M})$ ratios for the above three injured groups $(* P<0.05)$.

Abbreviations: CD, cyclodextrin; CDG2, PAMAMG2-g-cyclodextrin; cRGD, cyclic arginylglycylaspartic acid peptide; PAMAMG2, Generation 2 polyamidoamine; pVEGF, plasmid vector with the VEGF gene; VEGF, vascular endothelial growth factor.

VEGF expression can inhibit intimal thickening and then prevent restenosis after vascular injury induced by balloon angioplasty. In the present study, CDG2-cRGD and CDG2 were developed as vascular endothelial cell-targeted and nontargeted carriers, respectively, for intravascular delivery of the $p V E G F 165$ gene. cRGD targeting of injured vasculature by binding to $\alpha_{v} \beta_{3}$ integrins on vascular endothelial cells has been previously certified. ${ }^{28,29}$ Moreover, local intravascular gene delivery is a feasible approach for injured vasculature via a catheter or a drug-eluting stent placed in the newly widened part of the artery during an angioplasty procedure. Therefore, we anticipated that the combined application of cRGD conjugation and intravascular gene delivery would efficiently deliver the therapeutic gene $p V E G F 165$ in vivo by synergistically facilitating high specificity for the injured vasculature and targeted cellular uptake. Interestingly, the results of this study demonstrated that the stimulus response of balloon injury to arteries could obviously upregulate the VEGF165 expression in vivo observed in the salinetreated group, although it was not enough to prevent intimal

Table 2 The calculated intima area (I), media area (M), and I/M area ratios of the four groups

\begin{tabular}{llll}
\hline Group & Intima area $\left(\mu \mathrm{m}^{2}\right)$ & Media area $\left(\mu \mathrm{m}^{2}\right)$ & $\mathbf{I} \mathbf{M}$ \\
\hline CDG2-cRGD-5 & $64,243^{*}$ & 162,247 & $0.39 *$ \\
CDG2 & 169,728 & 174,836 & 0.97 \\
$0.9 \% \mathrm{NaCl}$ & 190,436 & 202,515 & 0.94 \\
Control & $/$ & 152,045 & $/$ \\
\hline
\end{tabular}

Note: $* P<0.05$, comparing with the CDG2 group and the $0.9 \% \mathrm{NaCl}$ group.

Abbreviations: CD, cyclodextrin; CDG2, PAMAMG2-g-cyclodextrin; cRGD, cyclic arginylglycylaspartic acid peptide; PAMAMG2, Generation 2 polyamidoamine. thickening and neointimal formation. In the gene-transfected groups, CDG2-cRGD-mediated gene delivery achieved the overexpression of VEGF165 protein, which was sufficient to allow efficient inhibition of intimal thickening after balloon angioplasty in rabbits, whereas the low therapeutic efficacy of the CDG2-treated group was only comparable to that of the saline-treated group.

Compared with CDG2, CDG2-cRGD exhibited significantly high gene transfection efficiencies in HUVECs and U87 cells showing high levels of $\alpha_{v} \beta_{3}$ integrin expression on the cell surface, but not in HEK293T cells with a very low level of $\alpha_{\mathrm{v}} \beta_{3}$ integrin expression (Figures 3 and 4). Most notably, the cRGD ligand density was an important factor that could greatly influence transfection activity in $\alpha_{v} \beta_{3}$ integrin-positive cells, namely, HUVECs and U87 cells. A relatively low cRGD density in CDG2-cRGD-2 (1.9 moieties per molecule) resulted in remarkably lower transfection efficiencies than CDG2-cRGD-5 (5.4 moieties per molecule) at all N/P ratios (Figure 4B and C). However, the high cRGD density in CDG2-cRGD-8 did not have a positive effect on transfection efficiency. It was previously reported by Montet et $\mathrm{al}^{39}$ and Waite and Roth ${ }^{40}$ that the "extra" RGD could not participate in $\alpha_{\mathrm{v}} \beta_{3}$ integrin binding and could even create steric hindrance when the density of RGD exceeded the density of RGD/integrin-binding sites displayed by the cell membrane. Therefore, the reduction in transfection activities in the presence of very high density of cRGD-modified CDG2 could be explained by decreased affinity to $\alpha_{v} \beta_{3}$ integrinpositive cells. The most significant enhancement of transfection efficiency in HUVECs was obtained using the formula 
containing pDNA/CDG2-cRGD-5 polyplex (N/P =7.5), which was used further for $p V E G F 165$ gene delivery.

It is well known that endothelial cells, in particular, primary endothelial cells, are not only notoriously difficult to transfect but also particularly susceptible to the toxic effects of transfection reagents. ${ }^{36}$ The proliferation assay indicated that both CDG2-cRGD and CDG2 induced much less cytotoxicity to HUVECs than did PEI $25 \mathrm{kDa}$ (Figure 2A). In addition, we observed that increasing the amount of CDG2-cRGD in the formulation (N/P ratios from 7.5 to 15.0) did not further improve the transfection efficiency of CDG2cRGD-5 (Figure 4B). It implied that RGD interaction with $\alpha_{\mathrm{v}} \beta_{3}$ integrins, facilitating the internalization of the pDNA polyplex into HUVECs, could be avoided using high concentrations of polycation gene carriers. The concentrationdependent charge interactions of the polycations, such as PEI $25 \mathrm{kDa}$, with the cell membrane have been found to promote transfection efficiency but induce significant cytotoxicity. ${ }^{41}$ Therefore, CDG2-cRGD-5 - having both high transfection efficiency as well as low cytotoxicity - has unambiguously proven the feasibility of $p V E G F 165$ gene transfer to vascular endothelial cells in vivo.

The specificity of cRGD conjugation in terms of binding the $\alpha_{\mathrm{v}} \beta_{3}$ integrin receptor has identified its critical contribution to the high transfection efficiency of the CDG2-cRGD. A competitive binding assay indicated that in the presence of competitive free cRGD, the transfection efficiencies of CDG2-cRGD-5 were dramatically reduced in both $\alpha_{\mathrm{v}} \beta_{3}$ positive cells, namely, HUVECs and U87 cells (Figure 5), demonstrating that the proposed carrier binds to cells through $\alpha_{v} \beta_{3}$ integrins. However, a complete abolishment of transfection was not observed, suggesting that the carrier binds also through other nonspecific interactions with the cells. ${ }^{42}$ CLSM observations further confirmed that attachment of the cRGD ligand greatly enhanced cellular internalization of the pDNA polyplex, compared with CDG2, in HUVECs that overexpress $\alpha_{\mathrm{v}} \beta_{3}$ integrin (Figure 6), apparently through receptor-mediated endocytosis. Moreover, among the various cRGD-coupling carriers, CDG2-cRGD-5 was the most efficient carrier for delivering pDNA into HUVECs, which is in good agreement with the transfection activity of the optimal formulation.

The efficient delivery of $p V E G F 165$ by CDG2-cRGD-5 was validated in HUVECs in terms of the expression levels of VEGF165 protein. Both ELISA and Western blot analysis demonstrated that after transfection, CDG2-cRGD-5 induced significantly increasing levels of VEGF165 protein expression (Figure 7), which would accelerate endothelial repairing and inhibit neointima formation after arterial injury. In contrast, CDG2 did not show a statistically significant enhancement in VEGF165 expression compared to control. The results indicated that cRGD modification is necessary for carriers to achieve efficient overexpression of VEGF165 protein and that electrostatic interactions are insufficient. The results of our in vitro studies illustrated the tremendous potential of CDG2-cRGD in delivering $p V E G F 165$ for targeting the injured vasculature because the expression of $\alpha_{v} \beta_{3}$ integrin is upregulated generally after vascular injury.

It is notable that the results of induced overexpression levels of VEGF165 protein in vivo were correlated with the results of in vitro experiments (Figures 7 and 8), most probably because the local intravascular administration route bypassed extracellular barriers. Hutter et $\mathrm{al}^{24}$ reported, after systemic injection of recombinant adenovirus human VEGF, that the transgenes were overexpressed in the liver and not at the site of endothelial denudation and arterial injury. In our studies, the pVEGF165/CDG2-cRGD-5 polyplex was administered with a catheter by the local intravascular route in rabbits after vascular injury, which allowed pVEGF165 to be delivered directly to the site of angioplasty without exposing the entire circulation to the medication. The in vivo results demonstrated that the expression level of VEGF165 protein in the CDG2-cRGD-5 group was significantly elevated compared with that in the CDG2 group $(P<0.01)$ (Figure 8$)$. This is consistent with previous studies ${ }^{17,20}$ that on arrival at the target site, the ligand-conjugated delivery systems provide benefits in terms of cellular internalization.

Most importantly, we observed that VEGF165 was overexpressed in both gene-transfected groups and salinetreated group undergoing balloon angioplasty, compared with the noninjured control group, while the therapeutic effect of VEGF165 on the inhibition of intimal thickening was significantly different among the three injured groups. The level of endogenous VEGF165 in the vascular wall was low under normal physiological conditions (Figure 8). After arterial injury, the endogenous VEGF165 levels were obviously upregulated in the saline-treated group. Upregulation of VEGF, which plays a significant role in spontaneous reendothelialization, is thought to have an autocrine effect in the arterial response-to-injury process. ${ }^{24}$ However, upregulation of endogenous VEGF165 expression in the saline-treated group did not efficiently inhibit intimal thickening. In the gene-transfected groups, rabbits that received $p V E G F 165 / C D G 2$ gene transfer revealed comparable severity of intimal thickening in injured arteries when compared with the saline-treated group, whereas treatment 
with pVEGF165/CDG2-cRGD-5 polyplex was associated with significantly less intimal thickness $(P<0.05)$ (Figure 9). It is becoming increasingly clear that the conflicting results of VEGF 165 gene therapy in two gene-transfected groups are reflective of the pivotal role of the cRGD-conjugated carriers as targetable gene delivery systems in achieving the beneficial therapeutic effects.

\section{Conclusion}

This study highlights the potentially important difference in delivery of pVEGF165 between vascular endothelial celltargeted and nontargeted polymeric gene delivery carriers for inhibition of intimal thickening after arterial injury. Here, CDG2-cRGD-5 was developed and optimized as the targetable carrier by conjugating an $\alpha_{\mathrm{v}} \beta_{3}$ integrin-binding cRGD peptide (average number of 5.4 cRGD moieties per molecule) into the nontargeted polycation CDG2. CDG2cRGD-5 achieved much higher transfection efficiency than CDG2 in $\alpha_{\mathrm{v}} \beta_{3}$-positive cells, namely, HUVECs and U87 cells. The specificity of cRGD in binding to the $\alpha_{v} \beta_{3}$ integrin receptor expressed on the cell surface and the subsequent enhanced intracellular uptake identified its critical contribution to the high transfection efficiency of CDG2-cRGD-5. The increased expression levels of VEGF 165 induced by the CDG2-cRGD-5 polyplex were remarkably higher than those induced by the CDG2 polyplex both in vitro and in vivo. Furthermore, local intravascular delivery of pVEGF165 using the CDG2-cRGD-5 polyplex in rabbits after vascular injury resulted in significantly less intimal thickening in comparison with the CDG2-transfected and saline-treated groups. Therefore, CDG2-cRGD-conjugated carriers have great potential as targetable gene delivery systems for improving effectiveness in vascular gene therapy.

\section{Acknowledgment}

The authors gratefully acknowledge the National Natural Science Foundation of China for extending financial support (project number 31170918) for this research.

\section{Disclosure}

The authors report no conflicts of interest in this work.

\section{References}

1. Gandhi NS, Tekade RK, Chougule MB. Nanocarrier mediated delivery of siRNA/miRNA in combination with chemotherapeutic agents for cancer therapy: current progress and advances. J Control Release. 2014;194C: 238-256.

2. Yin RX, Yang DZ, Wu JZ. Nanoparticle drug-and gene-eluting stents for the prevention and treatment of coronary restenosis. Theranostics. 2014; 4(2):175-200.
3. Won YW, Bull DA, Kim SW. Functional polymers of gene delivery for treatment of myocardial infarct. J Control Release. 2014;195:110-119.

4. Mandel RJ, Burger C, Snyder RO. Viral vectors for in vivo gene transfer in Parkinson's disease: properties and clinical grade production. Exp Neurol. 2008;209(1):58-71.

5. Rothe M, Schambach A, Biasco L. Safety of gene therapy: new insights to a puzzling case. Curr Gene Ther. 2014;14(6):429-436.

6. Putnam D, Gentry CA, Pack DW, Langer R. Polymer-based gene delivery with low cytotoxicity by a unique balance of side-chain termini. Proc Natl Acad Sci U S A. 2001;98(3):1200-1205.

7. Park TG, Jeong JH, Kim SW. Current status of polymeric gene delivery systems. Adv Drug Deliv Rev. 2006;58(4):467-486.

8. Tiera MJ, Shi Q, Winnik FM, Fernandes JC. Polycation-based gene therapy: current knowledge and new perspectives. Curr Gene Ther. 2011; 11(4):288-306.

9. Yin H, Kanasty RL, Eltoukhy AA, Vegas AJ, Dorkin JR, Anderson DG. Non-viral vectors for gene-based therapy. Nat Rev Genet. 2014;15(8): 541-555.

10. Kircheis R, Schuller S, Brunner S, et al. Polycation-based DNA complexes for tumor-targeted gene delivery in vivo. J Gene Med. 1999; 1(2): $111-120$.

11. Ogris M, Brunner S, Schuller S, Kircheis R, Wagner E. PEGylated DNA/transferrin-PEI complexes: reduced interaction with blood components, extended circulation in blood and potential for systemic gene delivery. Gene Ther. 1999;6(4):595-605.

12. Lai TC, Bae Y, Yoshida T, Kataoka K, Kwon GS. pH-sensitive multiPEGylated block copolymer as a bioresponsive pDNA delivery vector. Pharm Res. 2010;27(11):2260-2273.

13. Mishra S, Webster P, Davis ME. PEGylation significantly affects cellular uptake and intracellular trafficking of non-viral gene delivery particles. Eur J Cell Biol. 2004;83(3):97-111.

14. Merkel OM, Librizzi D, Pfestroff A, et al. Stability of siRNA polyplexes from poly(ethylenimine) and poly(ethylenimine)-g-poly(ethylene glycol) under in vivo conditions: effects on pharmacokinetics and biodistribution measured by fluorescence fluctuation spectroscopy and single photon emission computed tomography (SPECT) imaging. J Control Release. 2009;138(2):148-159.

15. Hyodo M, Sakurai Y, Akita H, Harashima H. "Programmed packaging" for gene delivery. $J$ Control Release. 2014;193:316-323.

16. Cheng Z, Al ZA, Hui JZ, Muzykantov VR, Tsourkas A. Multifunctional nanoparticles: cost versus benefit of adding targeting and imaging capabilities. Science. 2012;338(6109):903-910.

17. Bartlett DW, Su H, Hildebrandt IJ, Weber WA, Davis ME. Impact of tumor-specific targeting on the biodistribution and efficacy of siRNA nanoparticles measured by multimodality in vivo imaging. Proc Natl Acad Sci U S A. 2007;104(39):15549-15554.

18. Kirpotin DB, Drummond DC, Shao Y, et al. Antibody targeting of longcirculating lipidic nanoparticles does not increase tumor localization but does increase internalization in animal models. Cancer Res. 2006;66(13): 6732-6740.

19. McNeeley KM, Annapragada A, Bellamkonda RV. Decreased circulation time offsets increased efficacy of PEGylated nanocarriers targeting folate receptors of glioma. Nanotechnology. 2007;18(38):385101.

20. van der Meel R, Vehmeijer LJ, Kok RJ, Storm G, van Gaal EV. Ligandtargeted particulate nanomedicines undergoing clinical evaluation: current status. Adv Drug Deliv Rev. 2013;65(10):1284-1298.

21. Zhang Y, Satterlee A, Huang L. In vivo gene delivery by nonviral vectors: overcoming hurdles? Mol Ther. 2012;20(7):1298-1304.

22. Vicentini FT, Borgheti-Cardoso LN, Depieri LV, et al. Delivery systems and local administration routes for therapeutic siRNA. Pharm Res. 2013; 30(4):915-931.

23. Hoeben A, Landuyt B, Highley MS, Wildiers H, Van Oosterom AT, De Bruijn EA. Vascular endothelial growth factor and angiogenesis. Pharmacol Rev. 2004;56(4):549-580.

24. Hutter R, Carrick FE, Valdiviezo C, et al. Vascular endothelial growth factor regulates reendothelialization and neointima formation in a mouse model of arterial injury. Circulation. 2004;110(16):2430-2435. 
25. Thipparaboina R, Khan W, Domb AJ. Eluting combination drugs from stents. Int J Pharm. 2013;454(1):4-10.

26. Rutanen J, Turunen AM, Teittinen M, et al. Gene transfer using the mature form of VEGF-D reduces neointimal thickening through nitric oxide-dependent mechanism. Gene Ther. 2005;12(12):980-987.

27. Kishore R, Losordo DW. Gene therapy for restenosis: biological solution to a biological problem. J Mol Cell Cardiol. 2007;42(3):461-468.

28. Galvagni F, Orlandini M, Oliviero S. Role of the AP-1 transcription factor FOSL1 in endothelial cells adhesion and migration. Cell Adh Migr. 2013;7(5):408-411.

29. Liu S. Radiolabeled cyclic RGD peptides as integrin alpha(v)beta(3)targeted radiotracers: maximizing binding affinity via bivalency. Bioconjug Chem. 2009;20(12):2199-2213.

30. Tateishi U, Oka T, Inoue T. Radiolabeled RGD peptides as integrin alpha(v)beta3-targeted PET tracers. Curr Med Chem. 2012;19(20): 3301-3309.

31. Cao D, Qin L, Huang H, Feng M, Pan S, Chen J. Transfection activity and the mechanism of pDNA-complexes based on the hybrid of lowgeneration PAMAM and branched PEI-1.8k. Mol Biosyst. 2013;9(12): 3175-3186.

32. Huang H, Cao D, Qin L, et al. Dilution-stable PAMAM G1-grafted polyrotaxane supermolecules deliver gene into cells through a caveolaedependent pathway. Mol Pharm. 2014;11(7):2323-2333.

33. Pandita D, Santos JL, Rodrigues J, Pego AP, Granja PL, Tomas H. Gene delivery into mesenchymal stem cells: a biomimetic approach using RGD nanoclusters based on poly(amidoamine) dendrimers. Biomacromolecules. 2011;12(2):472-481.

34. Strauss BH, Chisholm RJ, Keeley FW, Gotlieb AI, Logan RA, Armstrong PW. Extracellular matrix remodeling after balloon angioplasty injury in a rabbit model of restenosis. Circ Res. 1994;75(4): 650-658.
35. Kawai J, Ando K, Tojo A, et al. Endogenous adrenomedullin protects against vascular response to injury in mice. Circulation. 2004;109(9): $1147-1153$

36. Hunt MA, Currie MJ, Robinson BA, Dachs GU. Optimizing transfection of primary human umbilical vein endothelial cells using commercially available chemical transfection reagents. J Biomol Tech. 2010;21(2): 66-72.

37. Lazarous DF, Shou M, Stiber JA, et al. Adenoviral-mediated gene transfer induces sustained pericardial VEGF expression in dogs: effect on myocardialangiogenesis. Cardiovasc Res. 1999;44(2):294-302.

38. Tsai WC, Li YH, Huang YY, Lin CC, Chao TH, Chen JH. Plasma vascular endothelial growth factor as a marker for early vascular damage in hypertension. Clin Sci (Lond). 2005;109(1):39-43.

39. Montet X, Funovics M, Montet-Abou K, Weissleder R, Josephson L. Multivalent effects of RGD peptides obtained by nanoparticle display. J Med Chem. 2006;49(20):6087-6093.

40. Waite CL, Roth CM. Binding and transport of PAMAM-RGD in a tumor spheroid model: the effect of RGD targeting ligand density. Biotechnol Bioeng. 2011;108(12):2999-3008.

41. Hunter AC. Molecular hurdles in polyfectin design and mechanistic background to polycation induced cytotoxicity. Adv Drug Deliv Rev. 2006; 58(14):1523-1531.

42. Ng QK, Sutton MK, Soonsawad P, Xing L, Cheng H, Segura T. Engineering clustered ligand binding into nonviral vectors: alphavbeta3 targeting as an example. Mol Ther. 2009;17(5):828-836. 


\section{Supplementary materials \\ Characterization of cRGD-conjugated \\ PAMAMG2-g-cyclodextrin (CDG2- CRGD)}

CDG2-cRGD was synthesized by a two-step cross-linking procedure. Supplementary Figure $\mathrm{S} 1$ was the ${ }^{1} \mathrm{H}-\mathrm{NMR}$ spectra of $\alpha-C D$, PAMAM G2, cRGD, CDG2, and CDG2-cRGD. Figure S1A showed the proton signals of $\alpha-C D(5.14 \mathrm{ppm}$ (s, C(a)H of $\alpha-C D), 4.07-3.89$ ppm (m, C(c) H, C(f) H and $\mathrm{C}(\mathrm{e})$ of $\alpha-\mathrm{CD}), 3.69-3.58 \mathrm{ppm}(\mathrm{m}, \mathrm{C}(\mathrm{b})$, and $\mathrm{C}(\mathrm{d}) \mathrm{H}$ of $\alpha-\mathrm{CD})$ ). These proton signals of $\alpha-C D$ became almost negligible in CDG2 because of the restriction of the molecular motion by grafting PAMAM G2 to $\alpha$-CD core, while proton signals of PAMAM G2 were distinctly observed (3.43-3.25 ppm (bm, C(i) H), 2.86-2.68 (m, C(j)H and C(g)H), 2.50-2.2.25 ppm (m, C(h) H)) (Figure S1B and D). For CDG2-cRGD, new proton signals at 6.48-7.32 ppm $(7 \mathrm{H}(\mathrm{k})$, br s, ArH Phe, $2 \times \mathrm{NH})$ were detected due to the conjugation of cRGD (Figure S1C and E).

\section{EGFP expression in transfected cells}

HEK293T, U87 and HUVEC cells were seeded into 24-well plates and preincubated for 24 hours. The transfection experiments were conducted at approximately $70 \%$ confluence. $100 \mu \mathrm{L}$ of pEGFPC1 polyplex and $0.4 \mathrm{~mL}$ of serum-free medium were added. The final pEGFPC1 concentration was $2.0 \mu \mathrm{g} /$ well. After transfection for 4 hours, the medium was replaced with fresh serum-containing medium and the cells were incubated for another 48 hours to enhance green fluorescent protein expression. The green fluorescence of transfected cells was observed by fluorescence spectroscopy (Olympus IX71 fluorescence spectroscope).

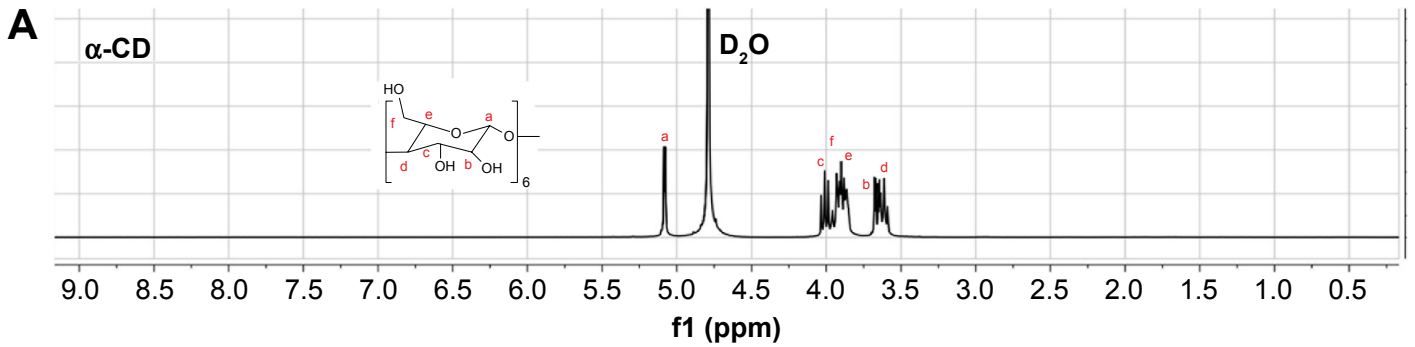

B
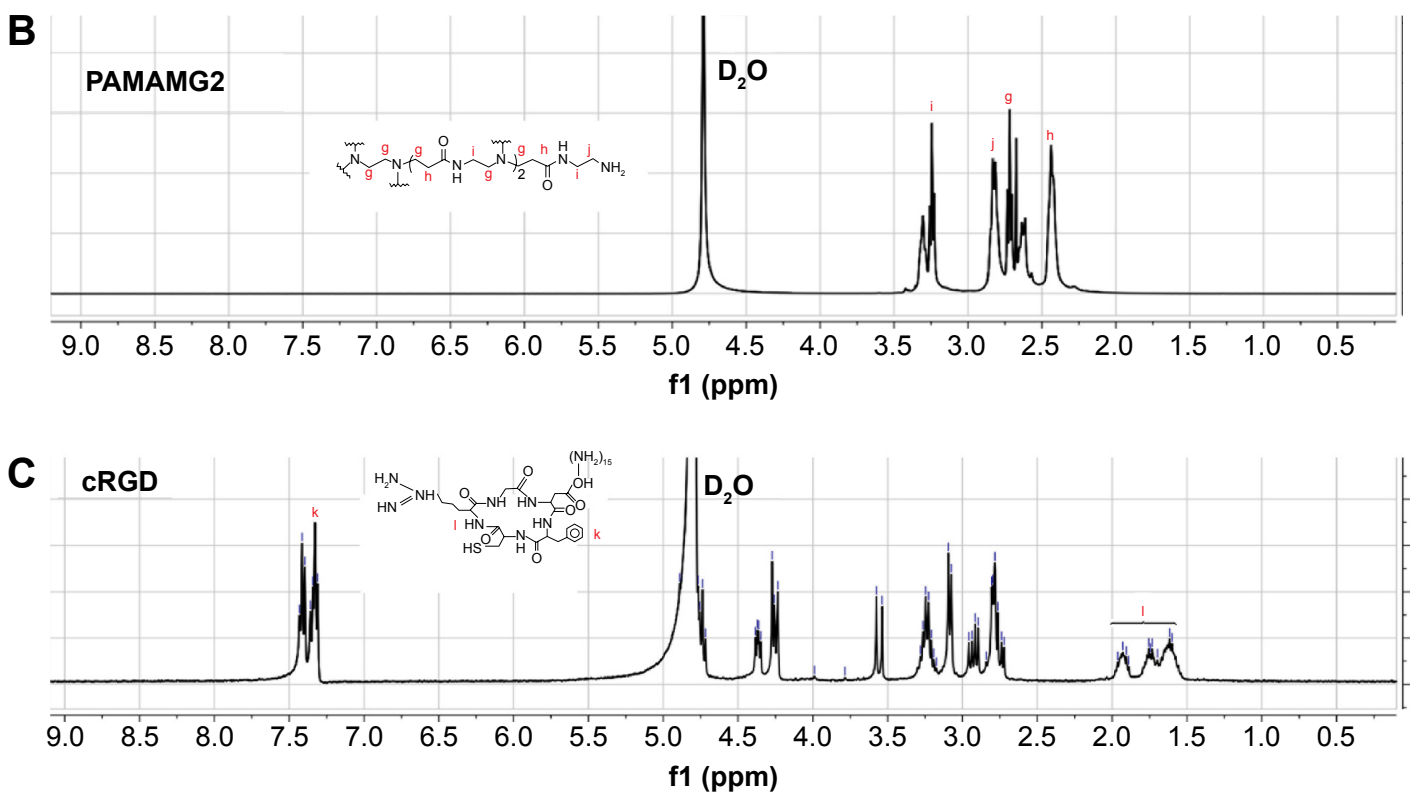

Figure SI (Continued) 

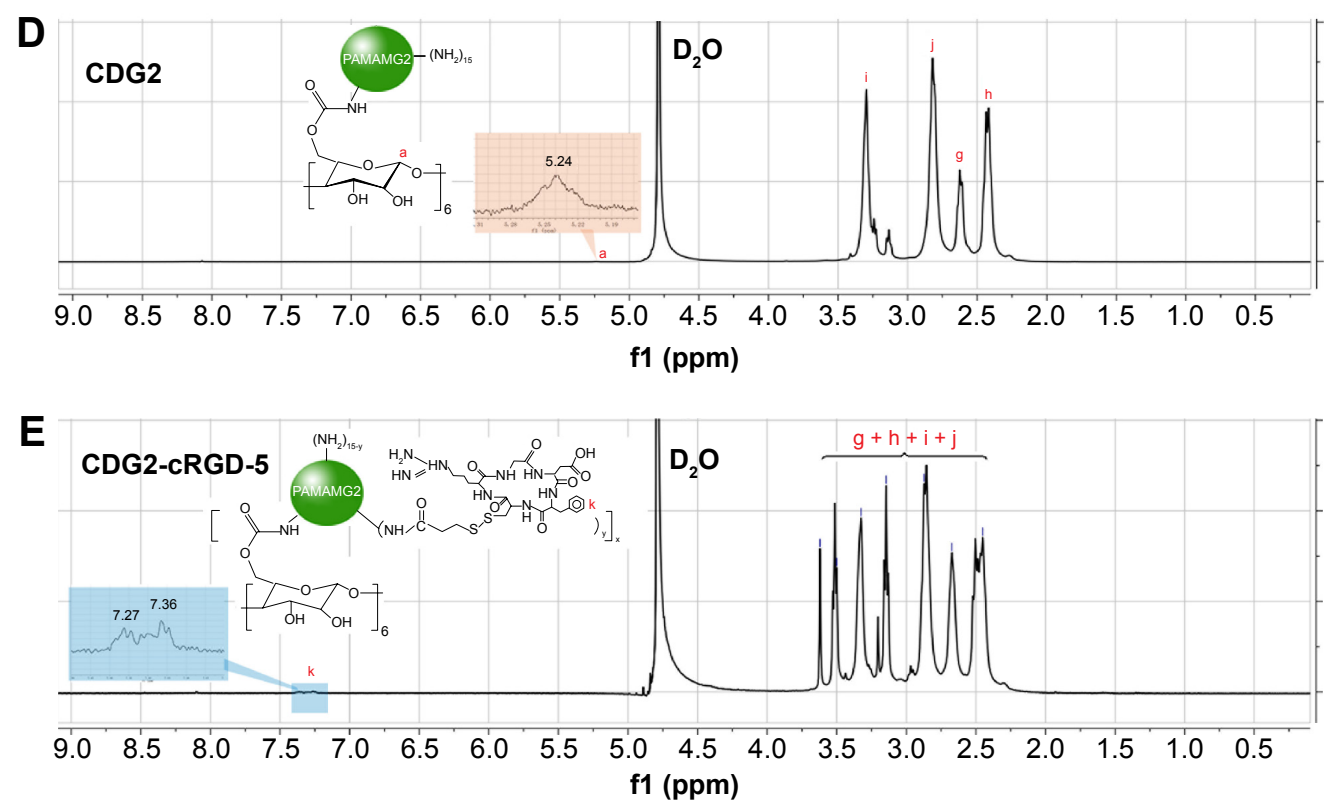

Figure SI 'H-NMR spectra of (A) $\alpha-C D$, (B) PAMAMG2, (C) cRGD, (D) CDG2, and (E) CDG2-cRGD.

Abbreviations: $C D$, cyclodextrin; CDG2, PAMAMG2-g-cyclodextrin; $c R G D$, cyclic arginylglycylaspartic acid peptide; $\mathrm{D}_{2} \mathrm{O}$, deuterium oxide; 'H-NMR, proton nuclear magnetic resonance; PAMAMG2, Generation 2 polyamidoamine.

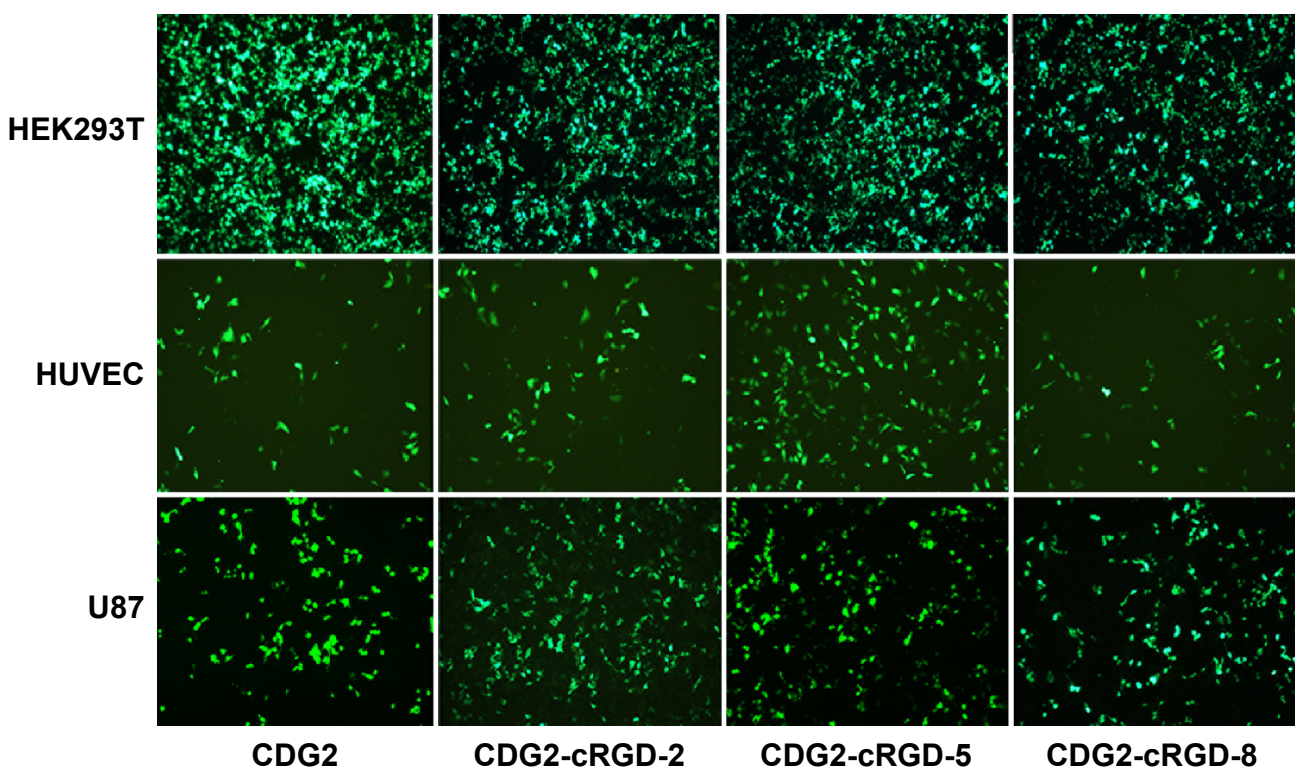

Figure S2 The relative transfection efficiencies of CDG2-cRGD conjugates.

Notes: EGFP expression after transfection with the conjugates was evaluated with FACS analysis in several different cell lines with varying levels of $\alpha_{v} \beta_{3}$ integrin receptor expression, which was observed by fluorescence spectroscopy. $200 \times$ magnification.

Abbreviations: CD, cyclodextrin; CDG2, PAMAMG2-g-cyclodextrin; cRGD, cyclic arginylglycylaspartic acid peptide; EGFP, enhanced green fluorescent protein; FACS, fluorescence-activated cell sorting; HEK 293T, human embryonic kidney cells; HUVEC, human umbilical vein endothelial cell; PAMAMG2, Generation 2 polyamidoamine; U87, human glioma cells.

\section{Publish your work in this journal}

The International Journal of Nanomedicine is an international, peerreviewed journal focusing on the application of nanotechnology in diagnostics, therapeutics, and drug delivery systems throughout the biomedical field. This journal is indexed on PubMed Central,

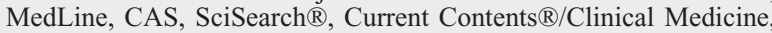

Journal Citation Reports/Science Edition, EMBase, Scopus and the Elsevier Bibliographic databases. The manuscript management system is completely online and includes a very quick and fair peer-review system, which is all easy to use. Visit http://www.dovepress.com/ testimonials.php to read real quotes from published authors. 